\title{
Is inexpensive natural gas hindering the grid energy storage industry?
}

Eric Hittinger ${ }^{\mathrm{a}, *}$, Roger Lueken ${ }^{\mathrm{b}}$

${ }^{a}$ Department of Public Policy, Rochester Institute of Technology, Rochester, NY 14623

(eshgpt@rit.edu)

${ }^{\boldsymbol{b}}$ The Brattle Group, 1850 M Street NW, Suite 1200, Washington, DC 20036

(Roger.Lueken@brattle.com)

*Corresponding Author: Phone: 585-475-5312, Fax: 585-475-2510

\begin{abstract}
Grid energy storage is a maturing technology and forecasts of the industry's growth have been promising. However, recent years have realized little growth in actual deployments of grid-level storage and several high-profile storage companies and projects have failed. We hypothesize that falling natural gas prices have significantly reduced the potential profit from many U.S. energy storage projects since 2009 and quantify that effect. We use engineering-economic models to calculate the monthly revenue to energy storage devices providing frequency regulation and energy arbitrage in several electricity markets and compare that revenue to prevailing natural gas prices. We find that flywheel devices providing frequency regulation were profitable in months when natural gas prices were above $\$ 7 / \mathrm{mcf}$, but face difficulties at current prices (around $\$ 4 / \mathrm{mcf}$ ). For energy arbitrage alone, we find that the breakeven capital cost for large-scale storage was around $\$ 300 / \mathrm{kWh}$ in several key locations in 2004-2008, but is around $\$ 100 / \mathrm{kWh}$ in the same locations today. Though cost and performance improvements have been continually decreasing the effective cost of energy services from storage, fundamental market signals indicating the need for energy storage are at or near 10-year lows for both energy arbitrage and frequency regulation.
\end{abstract}

Keywords: energy storage; capital cost; natural gas; frequency regulation; energy arbitrage

\section{Introduction}

Historically, electricity systems have had limited energy storage capacity. Energy storage today makes up less than $3 \%$ of total installed capacity in the U.S., almost all of which is in the form of pumped 
hydro storage (EPRI, 2010). Although energy storage can provide many services beneficial to the grid, high capital costs, technical issues, and regulatory difficulties have historically limited deployment. However, trends over the last twenty years have increased interest in energy storage: the difference between peak and off-peak load is increasing in most regions of the US, variable and intermittent renewables are being added at a rapid pace, and new energy storage technologies are being created and improved. Even though some grid storage technologies have been operating for decades, policy makers have only recently started discussing energy storage, resulting in storage mandates, subsidies, and storage-focused rulemaking from regulatory bodies. For example, the Storage Technology for Renewable and Green Energy Act (STORAGE) in 2013 proposed changes in the Internal Revenue Code of 1986, so that an energy investment credit would be provided for energy storage connected to the grid (US Senate Committee on Energy and Natural Resources, 113th Congress, 1st Session). In 2010, the California Senate passed AB2514, directing the California Public Utilities Commission (CPUC) to determine appropriate requirements for grid energy storage (AB 2514, 2010). Three years later, the CPUC mandated that the three major investor-owned utilities in California must collectively add $1.3 \mathrm{GW}$ of storage by 2020 (California Public Utilities Commission, 2013).

Since 2008, funding by the federal government for energy storage has increased substantially. The American Recovery and Reinvestment Act (ARRA) of 2009 provided \$185 million in federal funding for 16 storage projects (US Department of Energy, 2013). Total federal funding for battery and energy storage initiatives totaled \$1.3 billion for fiscal years 2009 - 2012. Along with funding research, the U.S. Department of Energy (DOE) has set cost reduction targets for storage technologies. DOE’s Office of Electricity Delivery has a target of \$250 / kWh for sodium-sulfur, lead-acid, lithium ion (Liion), and flow batteries (US DOE, Office of Electricity Delivery \& Energy Reliability, 2011). DOE’s Advanced Research Projects Agency- Energy (ARPA-E) has funded research into "revolutionary new technology approaches to grid-scale energy storage” with capital costs as low as \$100 / kWh (US DOE Advanced Research Projects Agency-Energy, 2010). 
These research and policy efforts have led to significant improvement into advanced energy storage technologies such as compressed air energy storage, electrochemical flow batteries, and flywheels. More mature storage technologies (Li-ion, nickel cadmium (NiCd), and lead-acid) are now deployed at utility scale. Several large grid energy storage projects have been commissioned since 2000 (Table 1). Based on this early activity and promising estimates of the value of grid energy storage (EPRIDOE, 2002) (Eyer, Iannucci, \& Corey, Energy Storage Benefits and Market Analysis Handbook, 2004), industry forecasts suggested exponential growth in the deployment of short-duration storage, such as batteries (Figure 1).

However, the industry has experienced some difficulties. Beacon Power, a prominent flywheel manufacturer, filed for bankruptcy in 2011 following the successful deployment of their New York flywheel frequency regulation plant. The firm was later acquired by Rockland Capital (Postelwait, 2013). The Iowa Stored Energy Park, a 270 MW, \$400 million project intended to integrate wind generation, was cancelled in 2011 due to unforeseen problems with the project's economics and geology. Sandia's Energy Storage Systems Program wrote a "lessons learned" report about this cancelled CAES plant (Schulte, Critelli, Holst, \& Huff, 2012). They state in the abstract of this report that one of the important lessons from the cancelled project is to carefully consider "...the costs and long-term economics of a CAES facility compared to conventional natural gas-fired generation alternatives". And the general trend of grid-level deployments of energy storage has been flat or declining for years, despite earlier predictions of rapid and robust growth in the market (Figure 2). The contrast between predictions of robust growth with low adoption of the technology leads to an obvious and important question: Why are actual deployments of energy storage lower than expected?

We hypothesize that falling natural gas prices have significantly reduced the potential profit from several types of U.S. energy storage projects since 2009, offsetting the technological improvements in storage technologies made over the same period. While this relationship has been proposed and discussed in the past, in this work we quantify its effect using historical data. Power generation from natural gas is 
a good substitute for many energy storage applications, including frequency regulation, energy arbitrage, and renewables integration. Furthermore, the price of wholesale natural gas has a large effect on the price at which natural gas generation and services are offered on the market because the levelized cost of electricity for natural gas generators is mostly due to fuel cost. For natural gas generation, $50-70 \%$ of the levelized cost of electricity is due to the fuel (US Energy Information Administration, 2014). This is not the case for other technologies such as coal power, for which fuel costs are less than $30 \%$ of the total cost of electricity. Furthermore, while all generators tend to bid close to their marginal costs, natural gas is an energy source with both higher average prices and higher price volatility than coal. Thus, decreasing natural gas prices (Figure 3) significantly decrease the cost of services from natural gas generation, which is perhaps the main competitor for grid energy storage in many applications. Stated another way, natural gas prices both have a stronger effect on the levelized cost of electricity and are historically more volatile than other fuels used to generate electricity, resulting in rapid and significant changes in the cost of grid electricity and services from gas turbines.

If this hypothesis is correct, a thorough examination of the relationship between natural gas price and the economics of energy storage is necessary to forecast the success of the nascent industry. As an emerging technology, energy storage is a "price taker", dependent on favorable electricity market prices and niche applications until it becomes more mature. Any significant shifts in the prevailing electricity prices, such as those occurring since 2009, will have an effect on price-taking technologies such as energy storage, putting economic competitiveness beyond any feasible technological improvement for some technologies. Additionally, many energy storage price and performance targets were based on economic analyses conducted from 2005 through 2009. Since that time, U.S. natural gas price has fallen as domestic production from shale gas has increased, and the conclusions of those analyses may no longer hold.

In this paper, we investigate the effect that natural gas price has on the profitability of storage projects. While we are not the first to propose such a link, we provide the first detailed quantitative 
evaluation of the relationship between natural gas price and the profitability of energy storage in two applications for energy storage: frequency regulation and energy arbitrage. Frequency regulation refers to the constant need to inject or remove small amounts of power from the grid to maintain a stable grid frequency. Both energy storage and natural gas generation are well suited to this application, as they can respond quickly to regulation requests. Energy arbitrage refers to the ability of storage to profit on wholesale energy markets by storing energy at low-priced hours and discharging at high-priced hours. Inexpensive natural gas competes with energy storage in this service by reducing peak prices and, therefore, the profitability of arbitrage with energy storage.

\section{Methods}

We evaluate the relationship between natural gas prices and the economics of owning and operating storage in two applications: frequency regulation and energy arbitrage. These applications are only two of many different services that grid energy storage can provide, but are both important and commonly discussed possible applications. In each case, we create an engineering-economic model of a storage device providing that service, and use electricity market price data to determine the net revenue produced by the storage. Once we have calculated the storage revenue, we vary the capital costs of storage to determine the "breakeven capital cost" - the capital cost at which the storage owner makes zero net revenue when accounting for amortized capital costs, operating costs, and revenues. In all analysis, we assume that the storage system is small enough that it displaces only the marginal generator and has no effect on market prices. This means that our results assume the best-case scenario for storage, as the effect of non-marginal storage participants will lower potential storage revenue in either service. 


\subsection{Frequency Regulation}

Frequency regulation is an ancillary service where a grid-level plant (generator or storage) agrees to change their power output on a second-by-second basis, following a signal sent from the system operator used to balance short-term differences in supply and demand. Functionally, this manifests as a semi-random signal with significant short-term variation, as shown in Figure 4. Participating plants bid into a frequency regulation market and are paid both a participation rate, in dollars per hour for each MW of service, and paid (or charged) for their net energy production (or consumption) during the period. Frequency regulation service has a limited market size but is an application where storage may be able to produce significant revenue (Eyer \& Corey, Energy Storage for the Electricity Grid: Benefits and Market Potential Assessment Guide, 2010) (Eyer, Iannucci, \& Corey, Energy Storage Benefits and Market Analysis Handbook, 2004) (Schoenung, 2001). Some energy storage technologies are well-suited to providing frequency regulation. For example, Beacon Power designed their primary product to provide this service (Beacon Power, 2011).

Market rules surrounding frequency regulation as applied to energy storage entities have been changing as a result of the 2011 Federal Energy Regulatory Commission Order 755, commonly known as the "mileage rule" (Federal Energy Regulatory Commission, 2011). This rule requires system operators to appropriately compensate fast-ramping resources for their ability to very closely follow the frequency regulation signal. Different system operators have responded (or plan to respond) to this rule in different ways. For example, in PJM there are now two different frequency regulation signals, Regulation A and Regulation D, each with their own time-varying signal and clearing price. Regulation A is the traditional service, and Regulation D is a faster-ramping signal designed for energy storage or other fast-ramping resources. Regulation D has stricter requirements for participation, smaller energy deviations, and a higher clearing price that the tradition Regulation A service. Importantly, in order to compare between NYISO and PJM and to compare between pre- and post-modification markets, we use the traditional frequency regulation signal and associated prices throughout this work. Additionally, public data on 
Regulation D signals and payments are currently unavailable. In the modified frequency regulation markets, flywheel plants are able to make more revenue, and those increases are not reflected in our calculations.

Our frequency regulation engineering-economic model calculates the net revenue resulting from one day of frequency regulation service with a flywheel device. This is calculated using a time-series model of the flywheel device providing the service, tracking power and energy into/out from the device and accounting for both conversion inefficiency and friction losses within the storage device. The flywheel is assumed to come in a discrete module with pre-defined properties based on Beacon Power's Smart Energy 25 flywheel (Beacon Power, 2011). In addition to round trip efficiency limitations, the flywheel model accounts for friction losses which reduce the stored energy over time (Table 2).

The flywheel operation is determined using a time-series model without any knowledge of future operation. The flywheel operation is broken into 15-min increments in which it charges/discharges as needed to meet the output required by the frequency regulation signal. In an attempt to maintain a 50\% state-of-charge, the flywheel plant purchases "bias" power in 15-minute increments. At each point in time, the net energy state of the flywheel is affected by energy out of or into the flywheel required for the frequency regulation service, energy losses due to internal friction, and energy in/out due to purchase/sale of power to maintain a $50 \%$ state of charge for the flywheel. This is shown in Equation 1, where $\mathrm{S}_{\text {fly }}$ is the flywheel state of charge, $\mathrm{E}_{\mathrm{fly}, \text { out }}$ and $\mathrm{E}_{\mathrm{fly} \text {,in }}$ are the energy out/in required by the frequency regulation service, $\eta_{\mathrm{RTE}}$ is the round-trip efficiency (set to $90 \%$ ), $\mathrm{P}_{\text {fric }}$ is the friction loss of the flywheel (set to $3 \mathrm{~kW}$ ), $\mathrm{T}_{\text {step }}$ is the time step of the model (set to 2 seconds), and $\mathrm{P}_{\text {bias }}$ is the power purchased to maintain the flywheel state of charge. Equation 2 shows how the power requirement of the frequency regulation service is converted into an energy equivalent, where $\mathrm{E}_{\text {fly }}$ is the energy into/out of the flywheel and $\mathrm{P}_{\text {fly }}$ is the power into/out of the flywheel. The initial state of charge for the flywheel is set to $50 \%$ of the maximum state of charge $\left(\mathrm{S}_{\max }\right)$ (Equation 3). Because the frequency regulation signal requires both discharges and charges from a flywheel, the ideal state of charge for a flywheel plant is $50 \%$. However, 
through friction losses or extended periods of charge/discharge, the actual flywheel state of charge will vary over time. To counteract this, the flywheel plant purchases or sells energy in 15-minute increments on the real-time market, and applies the purchased/sold power as a "bias" to the frequency regulation signal. Equation 4 shows how this bias power is calculated: every 15 minutes (the bias time, $\mathrm{T}_{\text {bias}}$ ), the flywheel plant purchases/sells the amount of power necessary to return the flywheel to a $50 \%$ state of charge over the next 15 minutes, assuming neutral operation of the flywheel over that period. Equations 5 and 6 state that there are upper and lower limits on the flywheel state of charge. Equations 7 and 8 state the limits on the power into/out from the flywheel, where $\mathrm{P}_{\mathrm{fly}, \max }$ is the maximum charge/discharge rate.

$$
\begin{aligned}
& \mathrm{S}_{\mathrm{fly}}(\mathrm{t})=\mathrm{S}_{\mathrm{fly}}(\mathrm{t}-1)-\mathrm{E}_{\mathrm{fly}, \mathrm{out}}(\mathrm{t}) * \sqrt{\eta_{\mathrm{RTE}}}+\frac{\mathrm{E}_{\mathrm{fly}, \mathrm{in}}(\mathrm{t})}{\sqrt{\eta_{\mathrm{RTE}}}}-\mathrm{P}_{\text {fric }} * \mathrm{~T}_{\text {step }}+\mathrm{P}_{\text {bias }} * \mathrm{~T}_{\text {step }} \\
& \mathrm{E}_{\mathrm{fly}}(\mathrm{t})=\mathrm{P}_{\mathrm{fly}}(\mathrm{t}) * \mathrm{~T}_{\text {step }} \\
& \mathrm{S}_{\mathrm{fly}}(1)=\frac{S_{\max }}{2} \\
& \left.\mathrm{P}_{\text {bias }}=\frac{\left(S_{\text {max }} / 2\right)-\mathrm{S}_{\mathrm{fly}}(\mathrm{t}-1)}{\mathrm{T}_{\text {bias }}} \quad \text { (recalculated every } 15 \text { minutes }\right)
\end{aligned}
$$

for all $t, E_{f l y}(t) \geq-P_{f l y, \max }$

Using frequency regulation data (Table 3) and the flywheel model, we calculate the maximum amount of frequency regulation service that a flywheel module can provide over the studied period. This is accomplished by re-running the model and slowly increasing the amount of provided regulation service until the modeled flywheel is no longer able to meet all of its dispatched charge/discharge. The frequency 
regulation signal data set consists of five days of 2-second resolution power requirements, made available by the PJM Interconnection (PJM, 2009). Frequency regulation prices are taken from New York Independent System Operator (NYISO) and PJM (New York ISO, 2014) (PJM, 2014).

The flywheel provides frequency regulation service continuously, resulting in a net consumption of energy (due to inefficiency and friction losses). Net consumption of electricity is calculated by determining both the electricity lost due to round-trip inefficiency and friction losses. An average electricity cost of $\$ 40 / \mathrm{MWh}$ is assumed for the net electricity consumed. However, at any fixed frequency regulation price, the cost of electricity consumed in operations has a trivial effect on the daily revenue for flywheel frequency regulation. When the average electricity price is varied for the purposes of sensitivity analysis, changes in electricity price (in \$/MWh) have an effect 1/100th as strong as the same change in frequency regulation price (in \$/MW-hour).

Once the quantity of frequency regulation service provided by the flywheel is determined, remaining financial calculations are straightforward. Average daily frequency regulation revenue is determined by multiplying the quantity of frequency regulation by the average hourly price of frequency regulation service during the period. Fixed operating costs and average daily electricity consumption costs are subtracted, producing an average daily net revenue. Daily revenue over the lifetime of the flywheel is discounted to present value (at 8\%) to produce a net present value of the operation of the flywheel, which is equal to the breakeven capital cost of the flywheel module. This method of calculation is mathematically equivalent to amortizing the capital costs over the lifetime of the device (at an $8 \%$ cost of capital), producing a daily loan payment for comparison with daily net revenue.

\subsection{Energy Arbitrage}

Energy arbitrage is a service that can be provided by grid energy storage where the storage is used to maximize revenue from time-shifting electrical energy from low price periods to high price periods. This is functionally similar to (but not exactly equivalent to) peak shaving, where a storage 
device attempts to reduce peak load by charging when demand is low and discharging during peak demand periods of the day. The vast majority of existing grid energy storage is in the form of pumped hydro storage, which generally operates to provide the energy arbitrage/peak shaving service that we model (Ela, et al., 2013). The potential market for energy arbitrage is very large - a cost-effective solution could be scaled up until it has significantly shifted wholesale electricity prices (Eyer \& Corey, Energy Storage for the Electricity Grid: Benefits and Market Potential Assessment Guide, 2010). However, energy arbitrage is also an application that requires inexpensive storage, due to the low potential profit margins (Eyer, Iannucci, \& Corey, Energy Storage Benefits and Market Analysis Handbook, 2004) (Schoenung, 2001) (Butler, Miller, \& Taylor, 2002).

Our energy arbitrage engineering-economic model does not model a particular storage technology. Rather, we model a generic storage device with attributes of existing or likely bulk storage technologies: pumped hydro, compressed air energy storage, and some battery technologies. Specifically, we model two devices. Our base case storage plant is a 20 MW / 80 MWh system (a "4-hour" device, simulating large batteries or fast-discharge CAES plants). To evaluate the effect that discharge rate has on operation and profit, we also model a 8 MW / 80 MWh system (a "10-hour" device, simulating pumped hydro or CAES). Both storage devices have a round-trip efficiency of 75\%, with the inefficiency divided equally between the charge and discharge portions of the cycle.

We model the operation of the storage plant under both perfect and imperfect information about future electricity prices. In either case, the storage owner pursues a strategy of maximizing revenue through energy arbitrage. The perfect and imperfect information cases act as bounds to the actual operation and revenue of energy storage systems. A real storage plant cannot exceed the revenue found in the perfect information case, but should be able to earn more revenue than the relatively simple imperfect information model, if operated with a reasonably sophisticated algorithm. 
The perfect information model uses a linear programming optimization to maximize revenue within the limitations of storage operation. Equations 9 to 16 express the optimization objective and constraints. We use an hourly time resolution for all energy arbitrage calculations. Prices are exogenous, and we assume storage to be a price taker.

The objective function (Equation 9) is to maximize revenue over the studied period, where $M_{t}$ and $E_{t}$ are the electricity price and electrical energy delivered from storage at time t. $E_{t}$ can be negative, representing the purchase of energy. The initial state of charge for the storage is $50 \%$ of maximum (Equation 10). Electrical energy into or out of the storage unit is subject to inefficiency, which is divided between the charge and discharge portions of the cycle (Equations 11 and 12), where $\eta_{R T E}$ is the roundtrip efficiency. $S_{t}$ represents the state of charge of the storage (in units of energy), $S_{\max }$ is the maximum state of charge, and $\mathrm{P}_{\max }$ is the maximum charge/discharge rate (in units of MW). Finally, the storage unit has upper and lower energy capacity limits (Equations 13 and 14) and charge/discharge rate limits (Equations 15 and 16).

$\max \sum M_{t} E_{t}$ such that

$S_{1}=\frac{S_{\max }}{2}$

$S_{t}=S_{t-1}-\frac{E_{t-1}}{\sqrt{\eta_{r T E}}} \quad$ if $E_{t-1} \geq 0$

$S_{t}=S_{t-1}-\sqrt{\eta_{R T E}} * E_{t-1} \quad$ if $E_{t-1}<0$

for all $t, S_{t} \geq 0$

for all $t, S_{t} \leq S_{\max }$

for all $t, \frac{E_{t}}{T_{\text {step }}} \leq P_{\max }$ 
for all $t, \frac{E_{t}}{T_{\text {step }}} \geq-P_{\max }$

The imperfect information model uses the same storage constraints as the model described above, but applies a simple "sell above, buy below" algorithm to determine when to charge or discharge. Storage is charged whenever the market clearing price is below a fixed "buy price", and discharged whenever the energy price is above a fixed "sell price". Between the buy and sell prices, the storage unit does nothing. Given the constraints described by Equations 10-16, the "sell above, buy below" algorithm follows Equations 17-19, where $\mathrm{M}_{\text {sell }}$ and $\mathrm{M}_{\mathrm{buy}}$ are the "sell" and "buy" prices guiding the storage operation.

For all $t$,

if $M_{t}>M_{\text {sell }}$ then $\max E_{t}$

if $M_{t}<M_{\text {buy }}$ then $\min E_{t}$

otherwise $E_{t}=0$

The buy and sell prices are recalculated for each month, as seasonal effects can shift the hourly electricity patterns. The buy and sell prices are determined for each scenario using a simulated annealing optimization that searches for revenue-maximizing values of buy and sell prices. The simulated annealing optimization follows the general algorithm described in Kirkpatrick et al (Kirkpatrick, Gelatt, \& Vecci, 1983), using an exponential decay for the temperature drop and runs the storage time-series model 10,000 times per scenario. In short, a simulated annealing search starts at an arbitrary point in the search space (in this case, where $\mathrm{M}_{\text {sell }}$ and $\mathrm{M}_{\text {buy }}$ are both set to the average electricity price) and searches nearby points in the search space. If an examined point is better (greater revenue, in this case), that new point becomes the default. If the new point is worse (lower revenue), there is a chance that the worse point will be used, though that probably decreases as the search progresses and as a function of how much worse the new point is. This allows the search to "get past" somewhat inferior solutions in a search space that is not entirely smooth. Given that there are only two input variables, a brute force search is also quite 
possible. However, the simulated annealing algorithm is used because it converges to effectively the same solution in a shorter time.

The operation of the storage device is quite different between the perfect and imperfect information scenarios. The imperfect information algorithm is a relatively simple approach that likely forms a lower bound on the likely arbitrage revenue. However, the revenue differences between perfect and imperfect information are small. Under perfect information about future electricity prices, the storage will operate more frequently (Figure 5). But this additional cycling of the storage device is in pursuit of smaller price differentials and has a smaller effect on net revenue. Many other approaches for optimizing the dispatch of energy storage providing energy arbitrage have been investigated, and could be used as an alternative to our approach (Connolly, Lund, Finn, Mathiesen, \& Leahy, 2011) (Drury, Denholm, \& Sioshansi, 2011) (Lund, Salgi, Elmegaard, \& Andersen, 2009) (Sioshansi, Denholm, \& Jenkin, A comparative analysis of the value of pure and hybrid electricity storage, 2011). Because this algorithm achieves revenues relatively close to the theoretical maximum observed under perfect information, we utilize the relatively simple imperfect information algorithm described above.

Most of the energy arbitrage results presented in this work use actual hourly real-time price data taken from PJM, NYISO, and ERCOT (PJM, 2014) (New York ISO, 2014) (ERCOT, 2011) and we use this data to show correlation between prevailing natural gas prices and potential revenue from a storage device. While we provide what we believe to be a compelling explanation of why natural gas prices affect storage revenue, the demonstrated correlation does not prove causation. As a way of validating the hypothesized causation between natural gas prices and storage revenue, we also use hourly price data generated by the PJM dispatch model PHORUM. PHORUM uses mixed integer linear optimization to find the least-cost combination of generators to meet load at all times (Lueken \& Apt, 2014). PHORUM simulates PJM day-ahead energy market, using 2010 data for fuel prices, transmission constraints, and the generation fleet. The model divides PJM into five buses, and solves for hourly locational marginal prices (LMPs) at each bus. Using PHORUM, we test the sensitivity of hourly LMPs to various natural gas 
prices, holding all other factors equal. In this way, we can isolate if natural gas price has a causal effect on hourly wholesale prices and energy storage revenue.

\subsection{Comparison with natural gas prices}

Our goal with this work is to examine the relationship between natural gas prices and energy storage net revenue, both of which vary over time. We calculate net revenue as total revenue earned from frequency regulation or energy arbitrage, minus operating costs, amortized capital costs, and costs of purchasing electricity. We calculate breakeven capital cost as the capital cost that results in total costs (fixed operating costs and amortized capital costs) equaling net revenue. All financial calculations are performed with standard project finance calculations, in 2012 real dollars, with capital costs amortized at a fixed $8 \%$ cost-of-capital.

Natural gas prices were taken from the US Energy Information Administration (US Energy Information Administration, 2014) and are adjusted to 2012 dollars.

\section{Results}

\subsection{Frequency Regulation}

The revenue that can be produced by a flywheel providing frequency regulation service is highly dependent on the frequency regulation price. Flywheel devices for frequency regulation generally do not provide any other services, nor do they consume any fuels that may have their own price volatility. In the two markets that we examined (PJM and NYISO), average frequency regulation price is highly correlated with the delivered price of natural gas to generators (Figure 6 and Figure 7). We focus on the NYISO and PJM regulation markets because they tend to have high frequency regulation prices and contain operational flywheel frequency regulation plants. 
Natural gas price can be expected to have an effect on frequency regulation clearing price because natural gas generators are able to provide frequency regulation service due to their generally high ramping capabilities. Thus, in systems with more gas turbines, there is more potential capacity for frequency regulation. However, a gas turbine must be operating to provide this service and it faces an opportunity cost: any spare capacity that a gas turbine uses as a reserve for frequency regulation cannot be used to deliver energy. As natural gas prices fall, we expect to observe several things that would put downwards pressure on frequency regulation prices: more gas turbines will be installed and they will operate during more hours of the year; also, peak electricity prices will decrease and thus decrease the opportunity cost of offering frequency regulation service.

Using linear regression, we formally test the relationship between regulation prices and fuel prices, including natural gas, in New York ISO (NYISO) and the PJM Interconnection (Equation 20). For PJM, we used nominal hourly regulation market clearing price (RMCP) data for from 2008 to 2013 (PJM, 2014). For NYISO, we used nominal 5-minute real-time RMCP data for the same time period (New York ISO, 2014). As predictor variables, we include the average monthly cost of fossil fuels (coal, natural gas, oil products) delivered to power plants. Fuel cost data are from EIA’s Electric Power Monthly (US Energy Information Administration, 2014). We used nominal delivered fuel price data for the state of Pennsylvania as a proxy for fuel prices in PJM and NYISO. Pennsylvania data was used because it was the most complete, with the least amount of data withheld to maintain anonymity over the time period (11 months withheld over six years). In our regression analysis, we omitted months with withheld fuel price data.

$$
R M C P=\beta_{0}+\beta_{1} \text { gasPrice }+\beta_{2} \text { coalPrice }+\beta_{3} \text { oilPrice }
$$

Table 5 and Table 6 show the results of our regressions. In PJM, a $\$ 1 / \mathrm{mcf}$ increase in the delivered price of natural gas is associated with a \$2 - \$3/MW-hour increase in average RMCP; in NYISO, a \$1/mcf in the delivered price of gas is associated with a \$3.5 - \$4.5/MW-hour RMCP increase. 
In both regressions, the p-value of the gasPricet variable is much less than 0.05 and we reject the null hypothesis that $\beta_{\text {gasPrice }}=0$. We therefore conclude that there is a highly significant $(\mathrm{p}<0.001)$ relationship between the delivered price of natural gas and frequency regulation price in both NYISO and PJM. The standard error of gasPrice in each regression is 0.5 , suggesting that the uncertainty of the coefficient is consistent between PJM and NYISO.

Both the sign and magnitude of the gasPrice coefficients are consistent with expectations. As gas turbines are typically the marginal generator supplying frequency regulation, we would expect reductions in their marginal costs to be associated with lower frequency regulation prices. The larger coefficient for NYISO relative to PJM may be in part due to the fact that gas generators make up a greater fraction of NYISO’s total generation capacity than in PJM. Using these coefficients, the $\sim \$ 8 /$ mcf decrease in natural gas prices between 2008 and 2014 is associated with a \$20/MW-hour decrease in PJM frequency regulation price and a \$32/MW-hour decrease in New York frequency regulation price. This is approximately what has been observed in the historical data.

The estimates of the coalPrice and oilPrice coefficients suggest that in each market, coal and oil prices have a much smaller effect on frequency regulation prices than does natural gas price. In PJM, the p-values of the coalPrice and oilPrice indicate the variables have no statistical significance. In NYISO, the coefficients are statistically significant, but much smaller than the gasPrice coefficient. The negative coalPrice coefficient suggests that if coal prices fell but gas prices remained constant, we would expect frequency regulation prices to rise. In reality, reductions in coal prices are typically accompanied by reductions in gas price, making interpretations of the coefficient difficult. A possible explanation is that a decrease in coal prices would cause coal to more frequently be the marginal generator providing frequency regulation. Because coal generators have slow ramp rates and are poorly suited to provide frequency regulation as compared to gas turbines, we would expect this to increase frequency regulation prices. 
We next calculate breakeven capital cost with our frequency regulation engineering-economic model. Breakeven capital cost is calculated monthly, assuming that the average frequency regulation price and natural gas price observed during a particular month persists indefinitely. As expected, the breakeven capital cost is strongly dependent on frequency regulation price. Figure 8 shows the breakeven capital cost of the flywheel versus natural gas price for each month, $2008-2013$. Overlaid on this plot are the estimated Beacon Power flywheel capital cost (EPRI-DOE, 2002) and the associated breakeven natural gas price. This capital cost ( $\$ 150 \mathrm{~K}$ - $\$ 250 \mathrm{~K}$ per module) is the expected future price under increased production and is significantly lower than the observed cost for the first flywheel frequency regulation plant, which had an installed capital cost of around \$350K per module (Clean Energy Action Project, 2012). Some points on Figure 8 show negative breakeven capital costs, which are for months where the frequency regulation revenue is itself insufficient to cover even the operating costs of the plant. These results suggest that a flywheel device with properties based on the Beacon Power design will only profitably provide frequency regulation services when natural gas prices are at or above the $\$ 5-8 / \mathrm{mcf}$ range.

\subsection{Energy Arbitrage}

In energy arbitrage, a storage device attempts to maximize net revenue by purchasing charging energy when electricity prices are low and selling the stored energy when electricity prices are high. Thus, energy arbitrage revenue is related to short-term variation in energy prices rather than average energy price. Figure 9 compares annual averages of natural gas prices and the daily variability in wholesale electricity prices (daily high price minus daily low price) in Washington, DC (PEPCO DC price node in PJM). Natural gas prices strongly affect variability in electricity prices because they dictate the marginal costs of generation from peaker natural gas turbines. Peaker turbines have low capital cost and moderate efficiency and are designed and operated to produce relatively expensive electricity for a few hours each day. A significant fraction of their levelized costs is due to fuel, so a decrease in natural gas price will decrease the price of electricity during peak periods each day. The marginal off-peak 
generator is likely to be a coal, combined cycle natural gas, or hydro plant (depending on location) and is less sensitive to fuel prices.

Figure 10 shows monthly natural gas prices and average storage revenue for Washington, DC under both perfect and imperfect information. Storage revenue is highest when daily price variation is highest, which is highly correlated with high natural gas prices. Figure 11 shows plots of monthly average energy arbitrage revenue versus natural gas prices for the 4-hour system in four locations. Figure 12 shows equivalent results for the 10 -hour system. While the scale of potential revenue varies significantly (about $4 \mathrm{x}$ in these locations), the relationship between natural gas price and average arbitrage revenue is similar across locations.

The correlation between high natural gas price and increased revenues is very pronounced. During peak natural gas prices of $\$ 10 / \mathrm{mcf}$, a storage device makes about three times as much on the realtime electricity market as it can when natural gas prices are \$3/mcf. Across the four locations examined, the base case 4-hour storage system has revenues in the $\$ 0-50 /$ hour range during months when natural gas prices were at $\$ 2 / \mathrm{mmbtu}$, which is approximately the historical low. In the few months when natural gas prices were around $\$ 12 / \mathrm{mmbtu}$, the same storage system has revenues in the $\$ 200-300 /$ hour range. For an application that is known to have slim profit margins, this significant change in potential revenue has a larger effect on profits than operating strategy, financing plans, or the design of the storage device.

For both the 4-hour and the 10-hour storage devices, average revenue falls to zero at a natural gas price around \$2/mmbtu. The 4-hour systems we investigated tend to make an additional \$20-30/hour for every $\$ 1 / \mathrm{mmbtu}$ increase in the natural gas price, while the 10 -hour device tends to earn $\$ 15$-25/hour more for every \$1/mmbtu price increase. The difference between the 4-hour storage system and the 10hour storage system is the most straightforward. In a given location, the 10 -hour system had average revenues that were approximately $38 \%$ lower (with a range of $36 \%$ to $41 \%$ across the four examined 
locations). This is unsurprising, as the 10-hour system has the same energy capacity but a lower charge/discharge rate and is less able to take advantage of short-term price variations.

Explaining the differences between locations is more complex. Arbitrage revenue in West Texas appears to be most sensitive to natural gas prices, perhaps because natural gas generation makes up a larger fraction of the overall generation mix in that region. West Texas also demonstrates the highest variance around the relationship between natural gas prices and arbitrage revenue. This may be due to more prominent confounding factors, such as the natural variability in wind resource in a region with a large installed base of wind turbines. Arbitrage revenue near Chicago is the least sensitive to natural gas price and the lowest at any given natural gas price. This is likely because of the lower utilization of natural gas generation in the region, resulting in a weaker coupling between natural gas prices and electricity prices. Even though these explanations are plausible, we should note that some of the observed trends and differences may result from unrelated factors (weather, market rules, capacity or transmission limitations) that may change in the future.

Our analysis shows that high natural gas prices are correlated with increased daily price variability and increased energy arbitrage revenue. However, other factors could theoretically explain the decreasing electricity price volatility we observe from 2008 - 2014. These factors could include changes in the aggregate load shape during and after the recession, or changes in the generation fleet due to retirements and new builds. To isolate if lower natural gas prices have a causal relationship on electricity price volatility and energy storage revenues, we used the PHORUM PJM grid model to generate hourly electricity prices given various natural gas prices as inputs (Lueken \& Apt, 2014). All other variables in the model are held constant, so all changes in electricity prices can be directly attributed to being caused by changes in natural gas price. Figure 13 shows annual average energy arbitrage revenue versus natural gas price using electricity price data generated by PHORUM. When we use the PHORUM-generated hourly price data to estimate energy arbitrage revenue, the results are very similar to those from actual 
price data presented above (Figure 11). We conclude that lower natural gas prices do cause reductions in energy arbitrage revenues.

We next calculate the breakeven capital cost for a storage device providing energy arbitrage. We apply an 8\% cost of capital, and do not include any operating costs except the cost of electricity. With these favorable assumptions and assuming perfect information about future electricity prices, the breakeven capital costs were always less than $\$ 400 / \mathrm{kWh}$ for a plant located near three major cities with high electricity price variability (Figure 14). During the 2005-2008 period, breakeven capital cost for an energy arbitrage storage device was around \$250/kWh. However, since 2009, the same storage device in the same location can only be profitable at a capital cost below $\$ 100 / \mathrm{kWh}$. This suggests that energy storage companies seeking to profit from energy arbitrage are likely facing significant financial challenges since 2009. For comparison, the ARPA-E GRIDS Program, which seeks "revolutionary new technology approaches to grid-scale energy storage", stated that it sought technologies with the potential to reduce costs to $\$ 100 / \mathrm{kWh}$ - a price which would only break even in many current electricity markets, even with perfect information about future electricity prices (US DOE Advanced Research Projects Agency-Energy, 2010).

\section{Discussion}

There has been a renewed focus on electrical energy storage technologies since the mid-2000s. This is unsurprising, as the economics of energy storage were relatively favorable during that period. Since then, patents, R\&D investments, and government interest have all been increasing. However, the deployment of grid energy storage remains limited. We believe that this can be partly explained by the effect that decreasing natural gas prices over the same period have had on the economics of grid energy storage in the two applications that we study. Since 2008, the energy storage industry has faced an unfortunate trend: as the new storage technologies have become ready for the market and the more mature 
technologies have lowered their costs, the decreasing cost of natural gas has been reducing the potential revenue of energy storage.

A significant amount of useful economic analysis on grid energy storage was performed by government and academic researchers using electricity price data from before the year 2009 (examples: (Butler, Miller, \& Taylor, 2002) (Eyer, Iannucci, \& Corey, Energy Storage Benefits and Market Analysis Handbook, 2004) (Figueiredo, Flynn, \& Cabral, 2006) (Sioshansi, Denholm, Jenkin, \& Weiss, 2009) (Walawalkar, Apt, \& Mancini, 2007) (EPRI-DOE, 2002)). These careful and respected analyses were used to establish the economic case for grid energy storage and helped to set price and performance targets for different classes of energy storage technologies. However, the relevant US electricity price trends since 2009 have been significantly different than in the preceding years. Energy storage companies or policy makers that rely on pre-2009 price targets or economic arguments for energy storage may not be aware that they poorly reflect present conditions.

Grid energy storage is often offered as a necessary solution to issues introduced by fluctuating wind and solar generation, implying that the existing grid assets are insufficient for accommodating renewable generation. If this were true, then existing price signals should indicate the need for storage. One would observe real-time prices collapsing when renewable generation picked up and price spikes when the power output dropped off unexpectedly. Alternately, if significant short-term variability was introduced by renewables, the frequency regulation price would be expected to increase. In actual fact, however, the opposite has been observed: since 2007, US wind and solar capacity has increased almost ten times (US Energy Information Administration, 2014), but real-time price variability and frequency regulation prices have both decreased. This is true even in West Texas, where significant wind development continues in an area of very little load. Despite large additions of wind power causing frequent negative prices during windy periods and prompting a significant expansion in transmission capacity out of the area, real-time price variability in West Texas has been decreasing since 2007 (Figure 11). Significant additions of natural gas capacity, combined with decreasing natural gas prices, are the 
likely explanation for this effect. Between 2000 and 2012, over 200 GW of natural gas generation was constructed in the US (Energy Information Administration, 2014). This is about 20\% of all electricity generating capacity in the country.

The implications of our results are not uniformly unfortunate for energy storage. While US prices for natural gas are low in 2015, they may start to rise in the near future due to increased demand. Projections for natural gas prices suggest only modest increases over the next decade, but natural gas prices have historically been quite volatile. In the Annual Energy Outlook 2015, the US Energy Information Administration forecasts that Henry Hub natural gas prices will rise from current prices in the $\$ 3-4 / m m b t u$ range up to $\$ 5-7 / \mathrm{mmbtu}$ by 2030 (US Energy Information Administration, 2015). This is a modest increase, and will likely be combined with significant short-term variability. Currently low natural gas prices are a result of the relatively sudden and unexpected increases in hydraulic fracturing of shale gas. The growth in supply has been rapid, and demand is still catching up. Export of liquefied natural gas (LNG), conversion of natural gas to chemical products, and increased demand for heating, transportation, or electricity generation may bring US gas prices up in the coming years, even with increasing supply. Rising prices would start to shift the effect on storage in the other direction, making grid energy storage more appealing.

Furthermore, the value of energy storage is greater than the revenue available from a specific energy service, as storage devices can serve multiple market services simultaneously. Thus, the systemwide benefit of storage is larger than the revenues calculated earlier. A recent study has shown that up to 5,000 MW of electricity storage would be cost effective in the ERCOT system if a range of system benefits are considered, including: avoided outages, deferred transmission and distribution investment, energy and regulation market cost savings, and avoided capacity investments (Chang, et al.). However, storage owners can only capture the value of these services if market structures include payments for them. There has been some recent progress in this regard, such as FERC Order 755 (the frequency regulation "mileage" rule) (Federal Energy Regulatory Commission, 2011) or the Reforming the Energy 
Vision (REV) initiative currently underway at the New York State Public Service Commission (New York State Public Service Comission, 2014). And there may be critical market opportunities for storage when market structures are carefully designed to compensate storage for superior performance, such as the much faster frequency regulation response provided by most storage devices. However, revenue decreases from the primary energy services provided by storage work in opposition to policy changes that improve revenue or provide other support to energy storage. In other words: though market rules and policy support are changing to better compensate for the many benefits of energy storage, the fundamental price signals indicating the need for storage services have been declining.

State and federal incentives for energy storage, such as the California storage mandate, may serve the role of helping the developing energy storage industry through a temporary difficult period. It may be the case that those mandates are not justified by immediate short-term grid benefits, but rather through the value of maintaining the health of the industry, allowing them to further develop products and services that will be available when natural gas prices once again increase.

Our results suggest that the storage industry should continue to emphasize applications for energy storage that do not directly compete with natural gas generators. These include most of the services provided by distributed energy storage, such as deferring the cost of new distribution lines or substation upgrades, improving reliability, and integrating distributed generation resources. These applications compete with distribution-level infrastructure such as power lines and transformers rather than transmission-level generators. Thus, it is unsurprising that much of the current focus of energy storage deployment plans (such as those resulting from the California storage mandate (California Public Utilities Commission, 2013)) is on these types of distribution-level activity. Furthermore, the United States is not the only potential market for grid energy storage. Because of the limitations of transporting LNG, the decrease in US natural gas prices has had a limited effect on prices in Europe, Japan, China, and other potential markets for grid energy storage. Storage companies may find that these regions currently have 
much more favorable economics for grid storage, and grid energy storage projects are being actively pursued in these areas (US Department of Energy, 2013).

\section{Conclusions and Policy Implications}

In this work, we have demonstrated that the direct revenue available to energy storage systems providing energy arbitrage or frequency regulation has been declining over the past 5-10 years in several US locations. Using a combination of real and simulated market price data, we link this decline in storage revenue to decreasing natural gas prices over the same period. Average energy arbitrage revenue and average frequency regulation revenue in the year 2012 are one half to one third of what they were in the 2004-2008 time period. This drastic shift in potential revenue is both a major obstacle to energy storage investment and a signal that energy storage is not currently needed for bulk energy arbitrage or frequency regulation. We additionally hypothesize that inexpensive natural gas is also negatively affecting the economic viability of some other energy storage applications beyond the two that we have studied. Importantly, though, there are some energy storage applications that do not compete with natural gas. While the two services we investigated were commonly discussed applications in the early 2000s, the focus of the storage industry has appropriately shifted somewhat towards distributed storage and other similar applications. Even though there have been significant improvements in storage performance and price over the last ten years, this technological progress is only slowly starting to result in appreciable deployments of energy storage.

There are several important implications of the trends presented above. First, industry and policy makers must be aware that the fundamental economics of energy storage have shifted significantly in the last ten years and that the conclusions of analysis using pre-2008 data may no longer apply. Second, while regulatory reforms and policy support have increasingly acknowledged the unique contribution of energy storage, future efforts must shift their focus towards better support of currently valuable applications for the technology, such as distributed storage. Third, decision makers should understand the 
relationship between natural gas prices and many of the grid-level services provided by energy storage. Specifically, energy storage policies should be created with an appreciation that the storage industry is currently experiencing temporarily adverse market conditions which have hindered deployments in the last six years.

\section{Acknowledgements}

This material is based upon work supported by the National Science Foundation under Award No. CMMI-1436469.

\section{Works Cited}

AB 2514. (2010, 8/23). Energy Storage Systems. Retrieved from http://www.leginfo.ca.gov/pub/0910/bill/asm/ab_2501-2550/ab_2514_cfa_20100823_113407_sen_floor.html

Beacon Power. (2011). Smart Energy 25 Flywheel. Retrieved June 2011, from Beacon Power: http://www.beaconpower.com/products/smart-energy-25.asp

Butler, P., Miller, J., \& Taylor, P. (2002). Energy Storage Opportunities Analysis Phase II Final Report. Sandia National Laboratories.

California Public Utilities Commission. (2013, October 17). Order Instituting Rulemaking Pursuant to Assembly Bill 2514 to Consider the Adoption of Procurement Targets for Viable and CostEffective Energy Storage Systems. Retrieved from Southern California Edison: https://www.sce.com/wps/wcm/connect/435ea164-60d5-433f-90bcb76119ede661/R1012007_StorageOIR_D1310040_AdoptingEnergyStorageProcurementFramew orkandDesignProgram.pdf?MOD=AJPERES

Chang, J., Pfeifenberger, J., Spees, K., Davis, M., Karkatsouli, I., Regan, L., \& Mashal, J. (n.d.). The Value of Distributed Electricity Storage in Texas: Proposed Policy for Enabling Grid-Integrated Storage Investments. Prepared for Oncor by The Brattle Group.

Clean Energy Action Project. (2012, May). Beacon Power Stephentown Advanced Energy Storage Case Study. Retrieved October 2014, from 
http://www.cleanenergyactionproject.com/CleanEnergyActionProject/CS.Beacon_Power_Steph entown_Advanced_Energy_Storage__Energy_Storage_Case_Study.html

Ela, E., Kirby, B., Botterud, A., Milostan, C., Krad, I., \& Koritarov, V. (2013, May). National Renewable Energy Laboratory. Retrieved January 2014, from The Role of Pumped Storage Hydro Resources in Electricity Markets and System Operation: http://www.nrel.gov/docs/fy13osti/58655.pdf

Energy Information Administration. (2014, July). EIA projects modest needs for new electric generation capacity. Retrieved December 2014, from http://www.eia.gov/todayinenergy/detail.cfm?id=17131

EPRI. (2010). Electricity Energy Storage Technology Options. Retrieved September 2011, from Electric Power Research Institute: http://my.epri.com/portal/server.pt?Abstract id $=000000000001020676$

EPRI-DOE. (2002). Handbook of Energy Storage for Transmission or Distribution Applications. EPRI-DOE.

ERCOT. (2011). DAY-AHEAD ANCILLARY SERVICES MARKET CLEARING PRICES FOR CAPACITY ARCHIVES. Retrieved October 2014, from http://www.ercot.com/mktinfo/prices/mcpc

Eyer, J., \& Corey, G. (2010). Energy Storage for the Electricity Grid: Benefits and Market Potential Assessment Guide. Sandia National Laboratories.

Eyer, J., lannucci, J., \& Corey, G. (2004). Energy Storage Benefits and Market Analysis Handbook. Sandia National Laboratories.

Federal Energy Regulatory Commission. (2011, October 20). Docket Nos. RM11-7-000 and AD10-11-000; Order No. 755; Frequency Regulation Compensation in the Organized Wholesale Power Markets. Retrieved January 2015, from http://www.ferc.gov/whats-new/comm-meet/2011/102011/E28.pdf

Figueiredo, F., Flynn, P., \& Cabral, E. (2006). The Economics of Energy Storage in 14 Deregulated Power Markets. Energy Studies Review, 14, 131-152.

Kirkpatrick, S., Gelatt, C. D., \& Vecci, M. P. (1983). Optimization by Simulated Annealing. Science, 220(4598), 671-680.

Lueken, R., \& Apt, J. (2014). The effects of bulk electricity storage on the PJM market. Energy Systems, 5, 677-704. doi:10.1007/s12667-014-0123- 7

NanoMarkets. (2009, August). Batteries and Ultra-Capacitors for the Smart Power Grid: Market Opportunities 2009-2016. Retrieved October 2014, from http://nanomarkets.net/images/uploads/SmartGridPBLES.pdf

New York ISO. (2014, October). Pricing Data. Retrieved October 2014, from http://www.nyiso.com/public/markets_operations/market_data/pricing_data/index.jsp 
New York State Public Service Comission. (2014). Reforming the Energy Vision (REV). Retrieved September 2014, from New York State Public Service Comission: http://www3.dps.ny.gov/W/PSCWeb.nsf/All/26BE8A93967E604785257CC40066B91A?OpenDoc ument

PJM. (2009). May 2009 Regulation Signal Components. Retrieved December 12, 2010, from PJM Market Based Regulation: http://www.pjm.com/markets-and-operations/ancillary-services/mkt-basedregulation.aspx

PJM. (2014). PJM Data Miner. Retrieved October 2014, from http://www.pjm.com/markets-andoperations/etools/data-miner.aspx

PJM. (2014, October). PJM Regulation Zone Preliminary Billing Data. Retrieved October 2014, from http://www.pjm.com/markets-and-operations/market-settlements/preliminary-billingreports/pjm-reg-data.aspx

Postelwait, J. (2013, June 26). Beacon Power Emerges from Bankruptcy with New Energy Storage Project. Retrieved October 2014, from Renewable Energy World: http://www.renewableenergyworld.com/rea/news/article/2013/06/beacon-power-emergesfrom-bankruptcy-with-new-energy-storage-project

Schoenung, S. (2001). Characteristics and Technologies for Long- vs. Short-term Energy Storage. Sandia National Laboratories.

Schulte, R., Critelli, N., Holst, K., \& Huff, G. (2012, January). Lessons from lowa: Development of a 270 Megawatt Compressed Air Energy Storage Project in Midwest Independent System Operator. Retrieved October 2014, from sandia.gov: http://www.sandia.gov/ess/publications/120388.pdf

Sioshansi, R., Denholm, P., Jenkin, T., \& Weiss, J. (2009). Estimating the Value of Electricity Storage in PJM: Arbitrage and Some Welfare Effects. Energy Economics, 31, 269-277.

US Department of Energy. (2013, December). Grid Energy Storage. Retrieved October 2014, from http://energy.gov/sites/prod/files/2013/12/f5/Grid\%20Energy\%20Storage\%20December\%2020 13.pdf

US Department of Energy. (2014, October). DOE Global Energy Storage Database. Retrieved October 2014, from http://www.energystorageexchange.org/projects

US Department of Energy. (2014, October). DOE Global Energy Storage Database. Retrieved October 2014, from http://www.energystorageexchange.org/projects

US DOE Advanced Research Projects Agency-Energy. (2010). Grid-Scale Rampable Intermittent Dispatchable Storage (GRIDS), Funding Opportunity Number: DE-FOA-0000290. Retrieved September 2011, from ARPA-E: https://arpa-efoa.energy.gov/FileContent.aspx?FileID=98c6222e-471c-4216-a377-024dbdb45549 
US DOE, Office of Electricity Delivery \& Energy Reliability. (2011, February). Energy Storage Program Planning Document. Retrieved June 2011, from US DOE:

http://www.oe.energy.gov/DocumentsandMedia/OE_Energy_Storage_Program_Plan_Feburary _2011v3.pdf

US Energy Information Administration. (2014, October). Electricity Data Browser. Retrieved October 2014, from http://www.eia.gov/electricity/data/browser/

US Energy Information Administration. (2014, April). Levelized Cost and Levelized Avoided Cost of New Generation Resources in the Annual Energy Outlook 2014. Retrieved October 2014, from http://www.eia.gov/forecasts/aeo/electricity_generation.cfm

US Energy Information Administration. (2014, October). Natural Gas Data. Retrieved October 2014, from http://www.eia.gov/naturalgas/data.cfm\#summary

US Senate Committee on Energy and Natural Resources. (113th Congress, 1st Session). STORAGE Act of 2013. Retrieved from US Senate Committee on Energy and Natural Resources: http://www.energy.senate.gov/public/index.cfm/files/serve?File_id=fedb4a77-7073-422db259-c8af7f59e627

Walawalkar, R., Apt, J., \& Mancini, R. (2007). Economics of Electric Energy Storage for Energy Arbitrage and Regulation in New York. Energy Policy, 35, 2558-2568. 
Figures

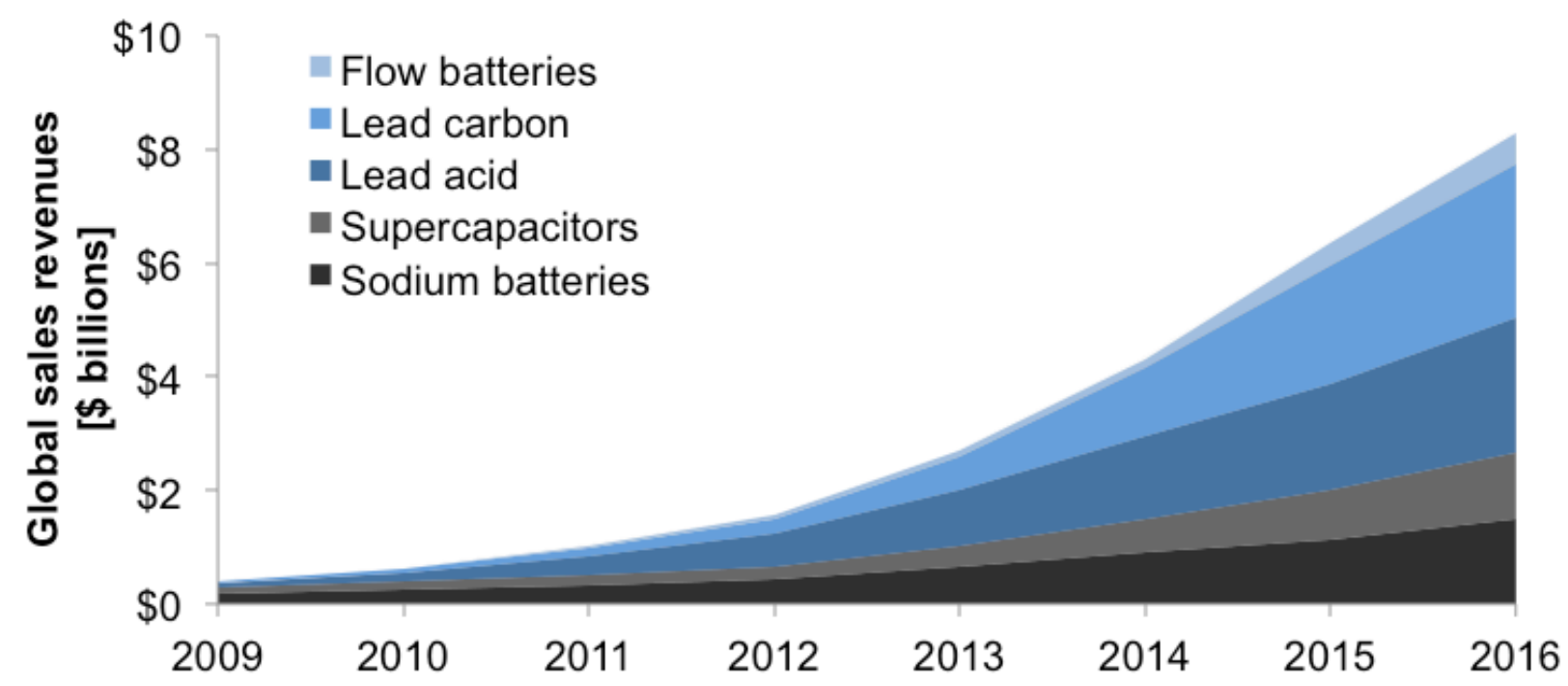

Figure 1. NanoMarkets' 2009 forecast of global sales revenues of smart grid energy storage (Data from (NanoMarkets, 2009)).

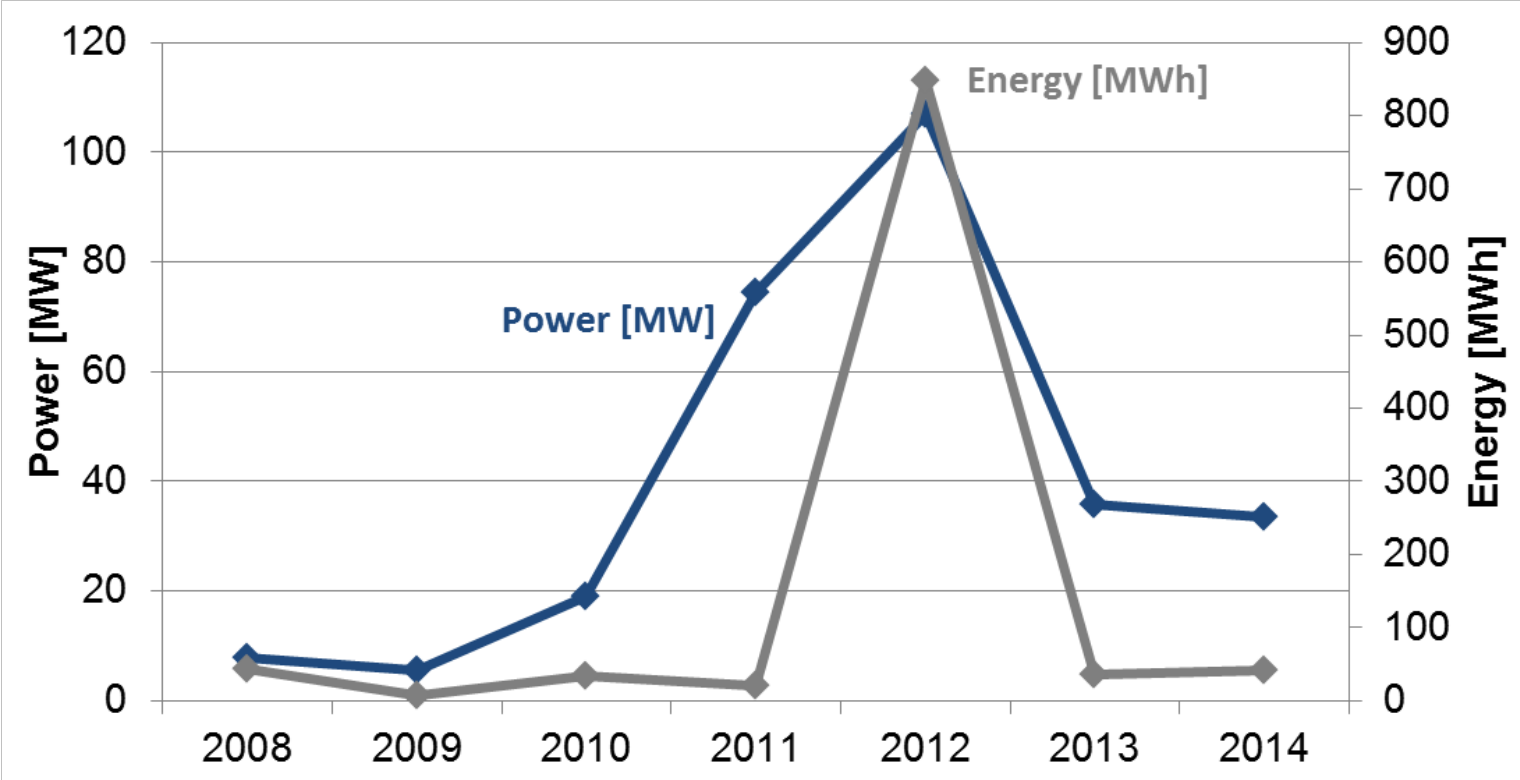

Figure 2. Total grid-tied energy storage capacity commissioned by year, 2008 - 2014 (US Department of Energy, 2014). Excludes thermal storage. Installed energy capacity [MWh] was high in 2012 due to the commissioning of the 8-hour duration Olivenhain-Hodges pumped hydropower facility. 


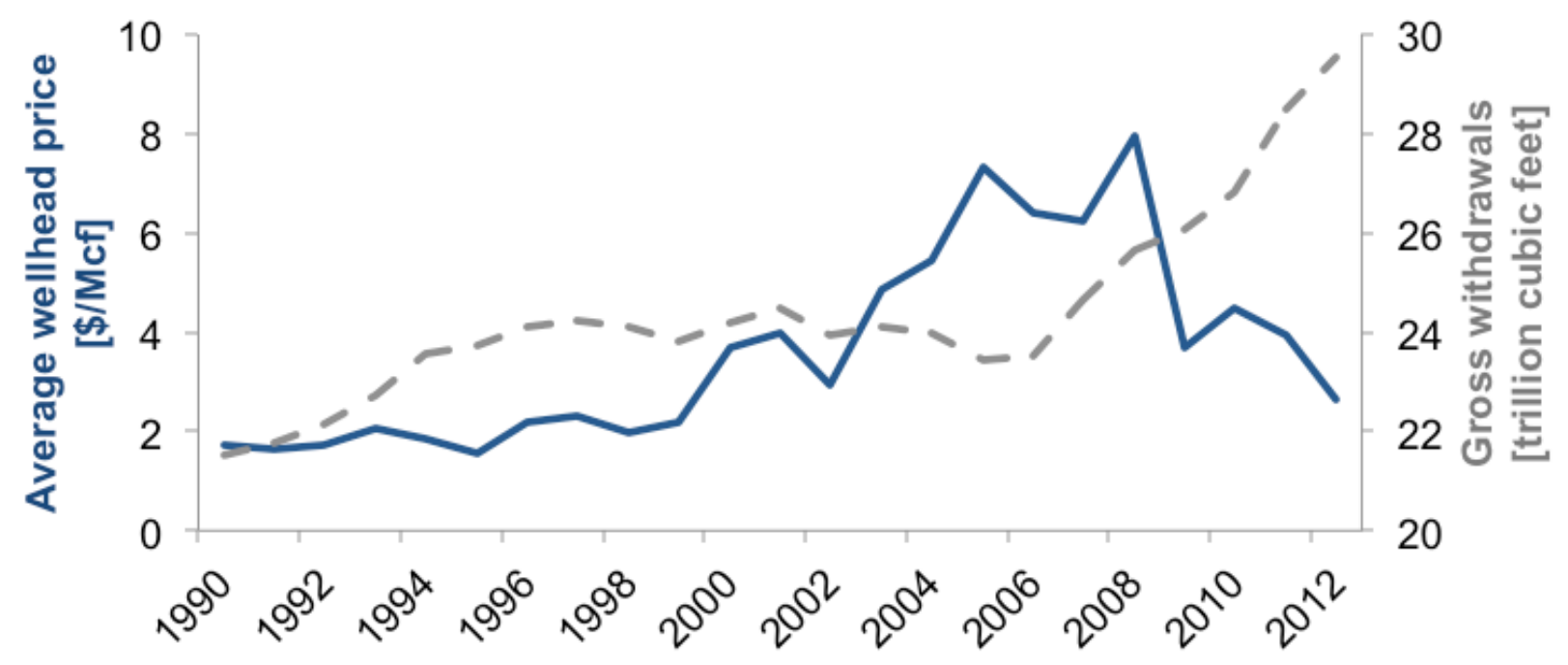

Figure 3. U.S. average natural gas wellhead price and annual gross withdrawals, 1990 - 2012. Data from US Energy Information Administration (US Energy Information Administration, 2014).

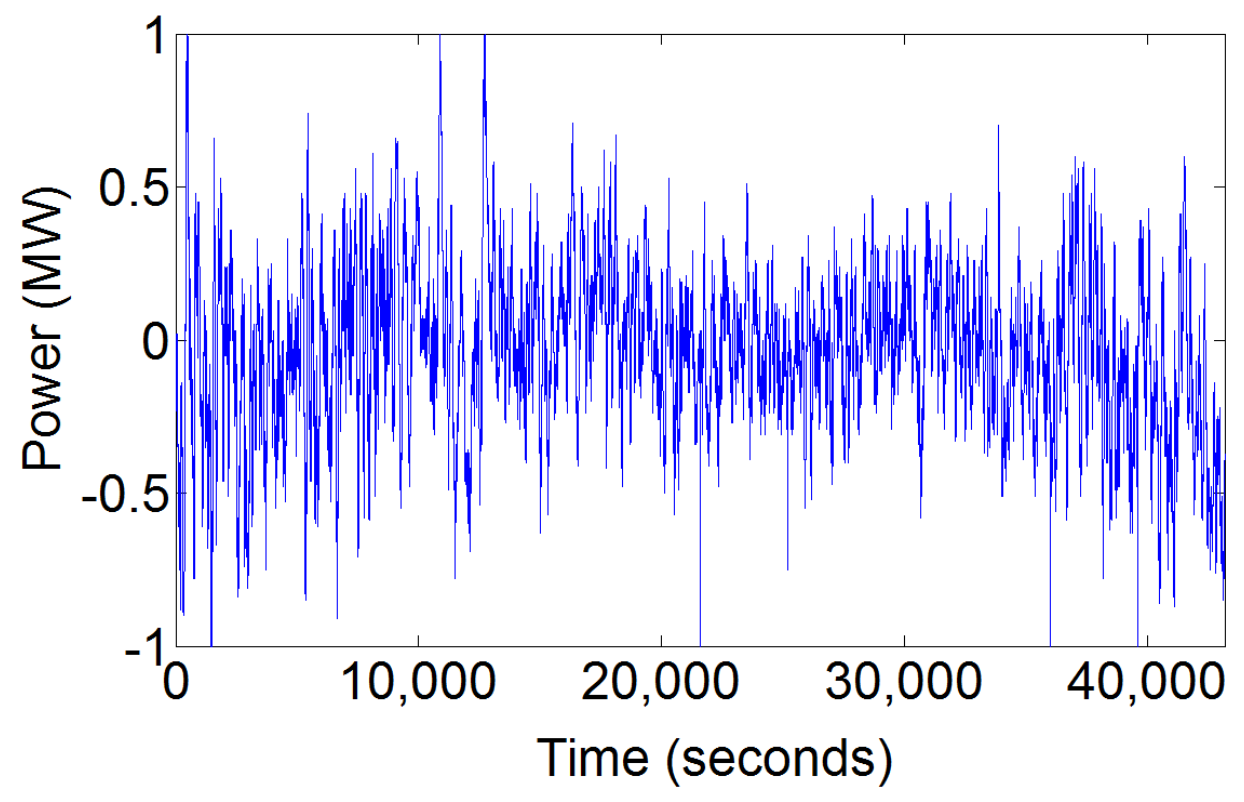

Figure 4: The power output required over one day of 1-MW frequency regulation service. Meeting the frequency regulation signal requires a generator or storage device to rapidly change its power output to follow a high-frequency (2-second, in this example) signal from the ISO. The source data are for one day in May 2009 in PJM (PJM, 2009). 


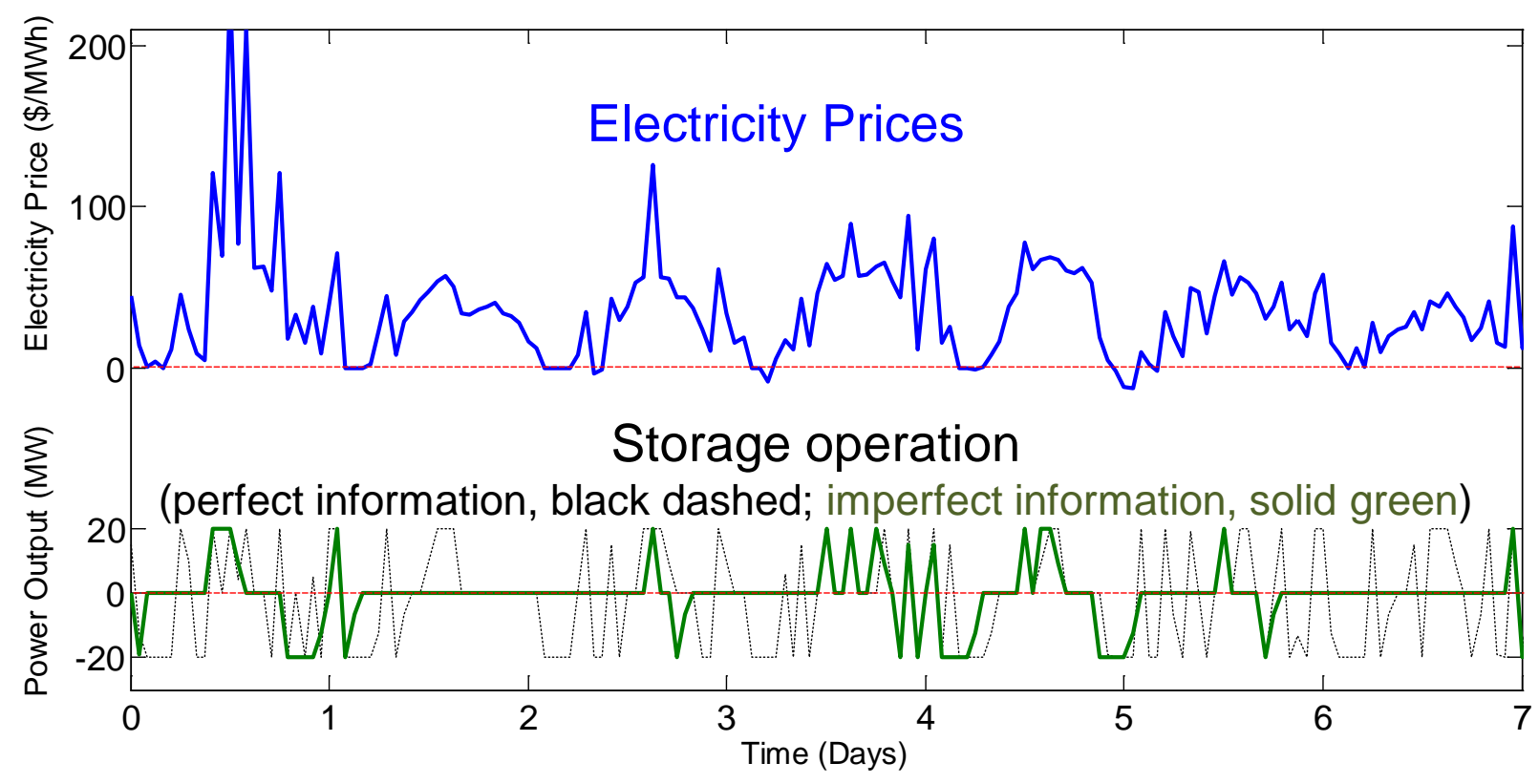

Figure 5: Comparison of perfect and imperfect information operation of an energy arbitrage storage unit. The figure shows electricity prices (top) and storage operation (bottom) under both perfect (black dashed) and imperfect (solid green) information. In both cases, storage tends to charge during periods of low price and discharge during high prices. Given perfect information about future electricity prices, storage operates far more frequently. However, this increased activity is in pursuit of smaller differences in price, and net revenue increases by only a small amount. The electricity price data is from West Texas in 2010.

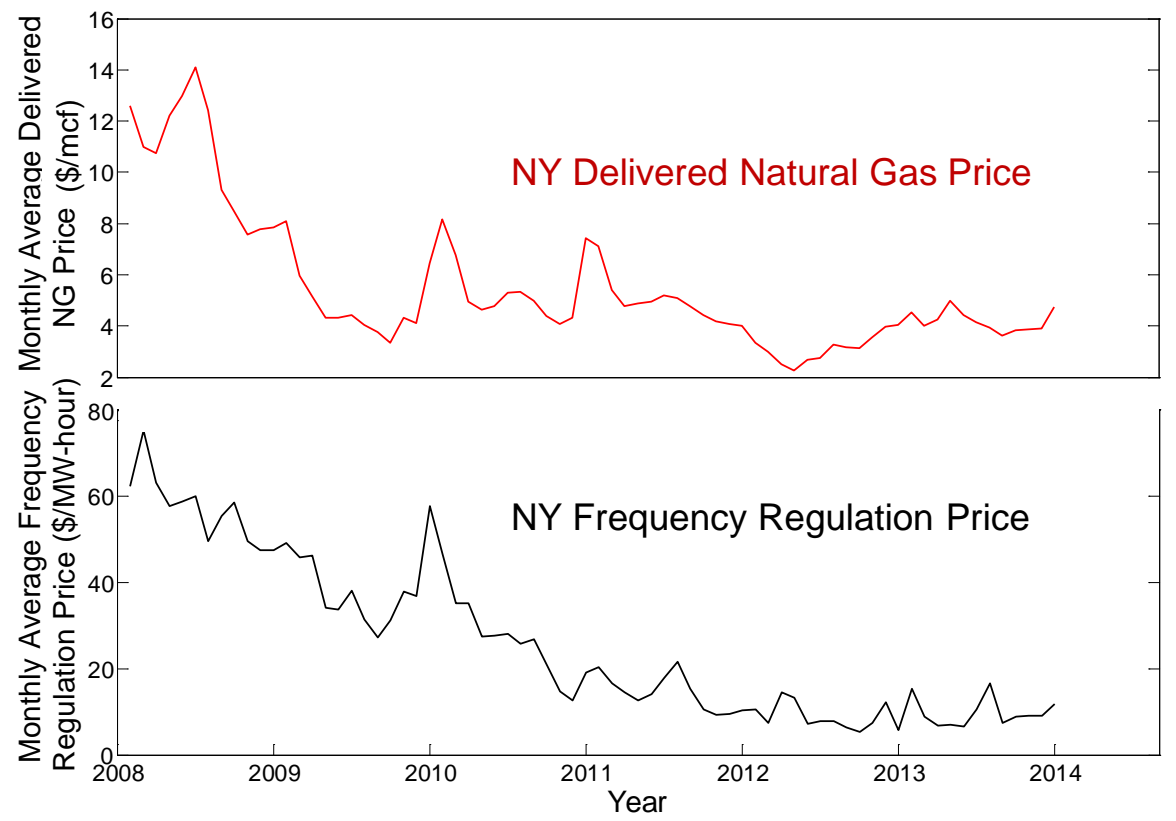

Figure 6: Monthly average delivered natural gas and frequency regulation prices in New York ISO from 2008 through 2013. 


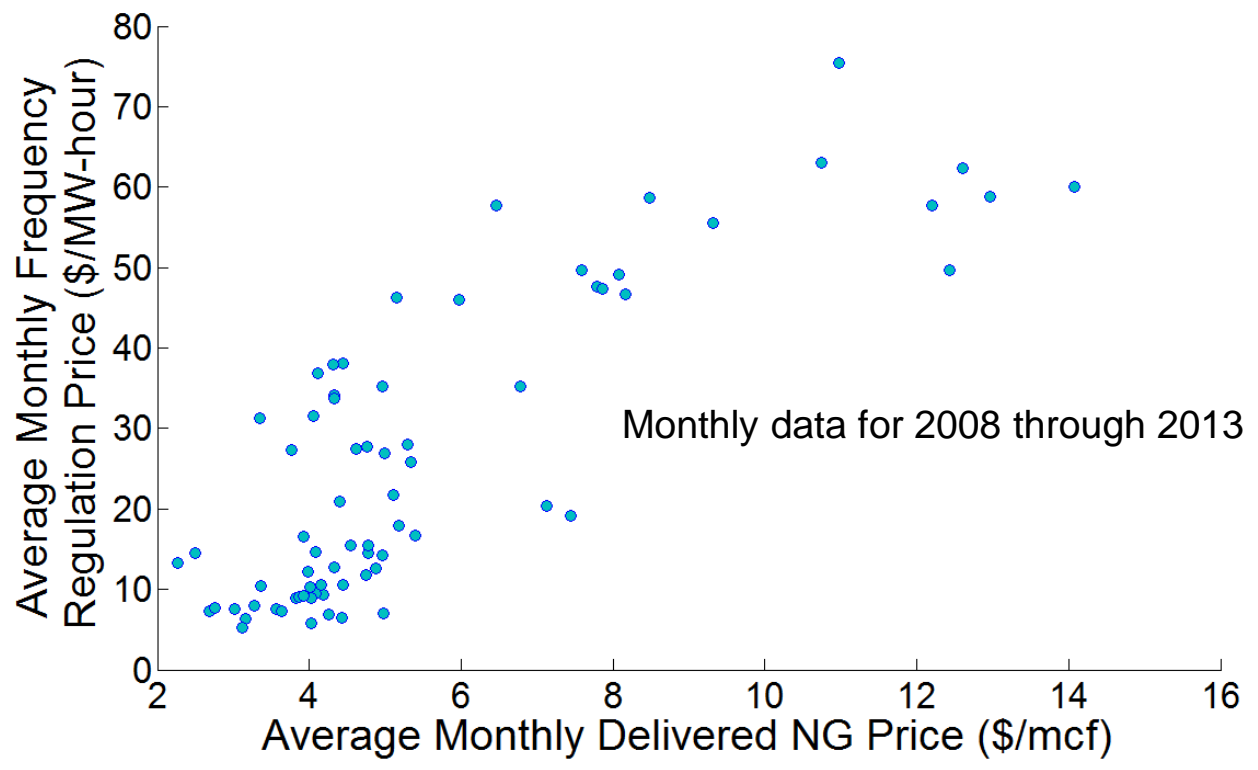

Figure 7: Plot of delivered natural gas price versus average frequency regulation price (both monthly averages from 2008 through 2013). These points represent the same data as Figure 6, for New York ISO.

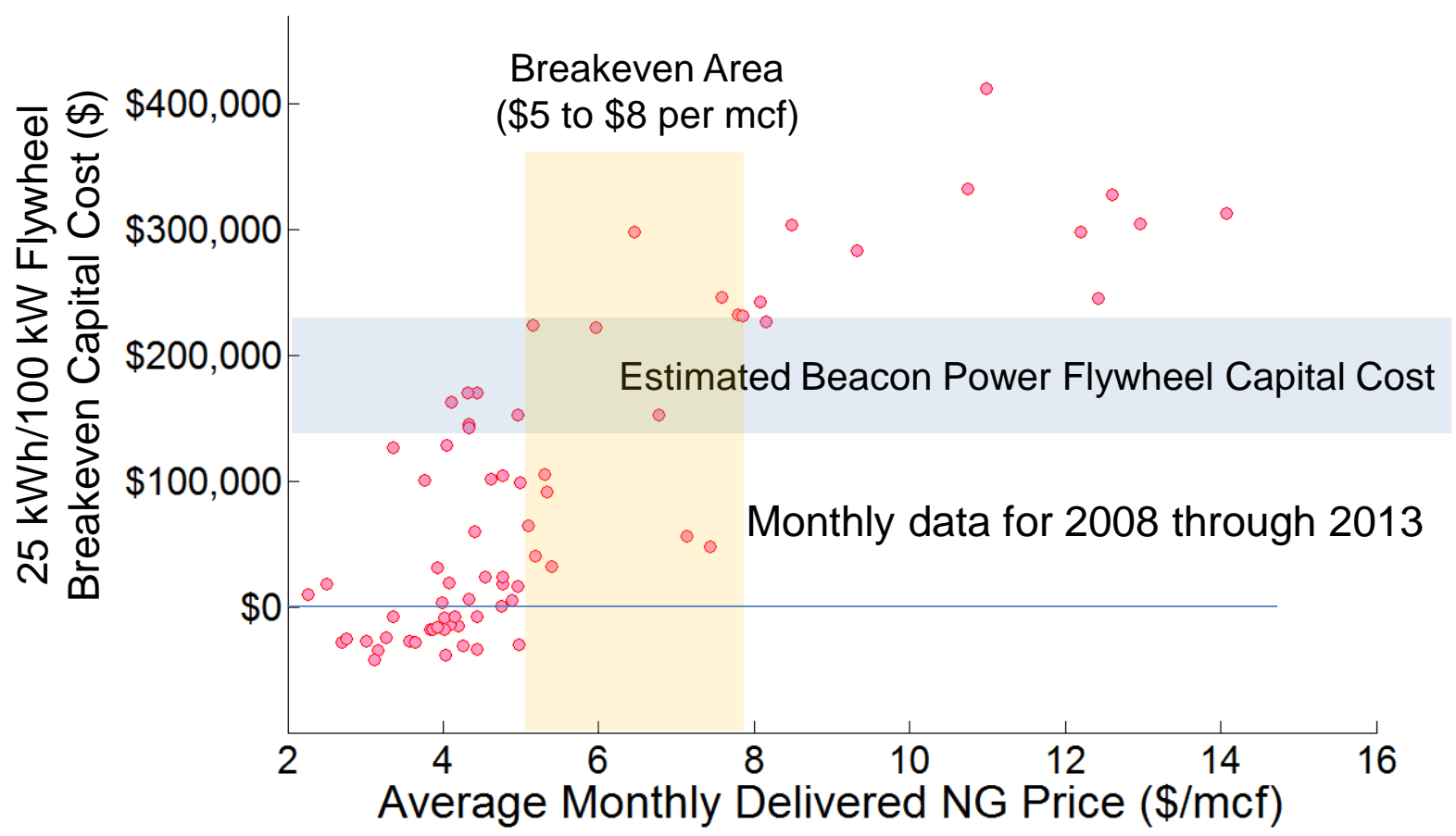

Figure 8: Average monthly delivered natural gas price versus breakeven capital cost of a flywheel. The estimated Beacon Power flywheel capital cost range and associated range of natural gas prices are overlaid onto the figure. Our results indicate that a flywheel device can break even only under frequency regulation prices associated with $\$ 5-8 / \mathrm{mcf}$ natural gas. Some points on this figure have a negative breakeven capital cost. This occurs when the revenue from frequency regulation service is insufficient to cover even the operating costs of the flywheel plant. 


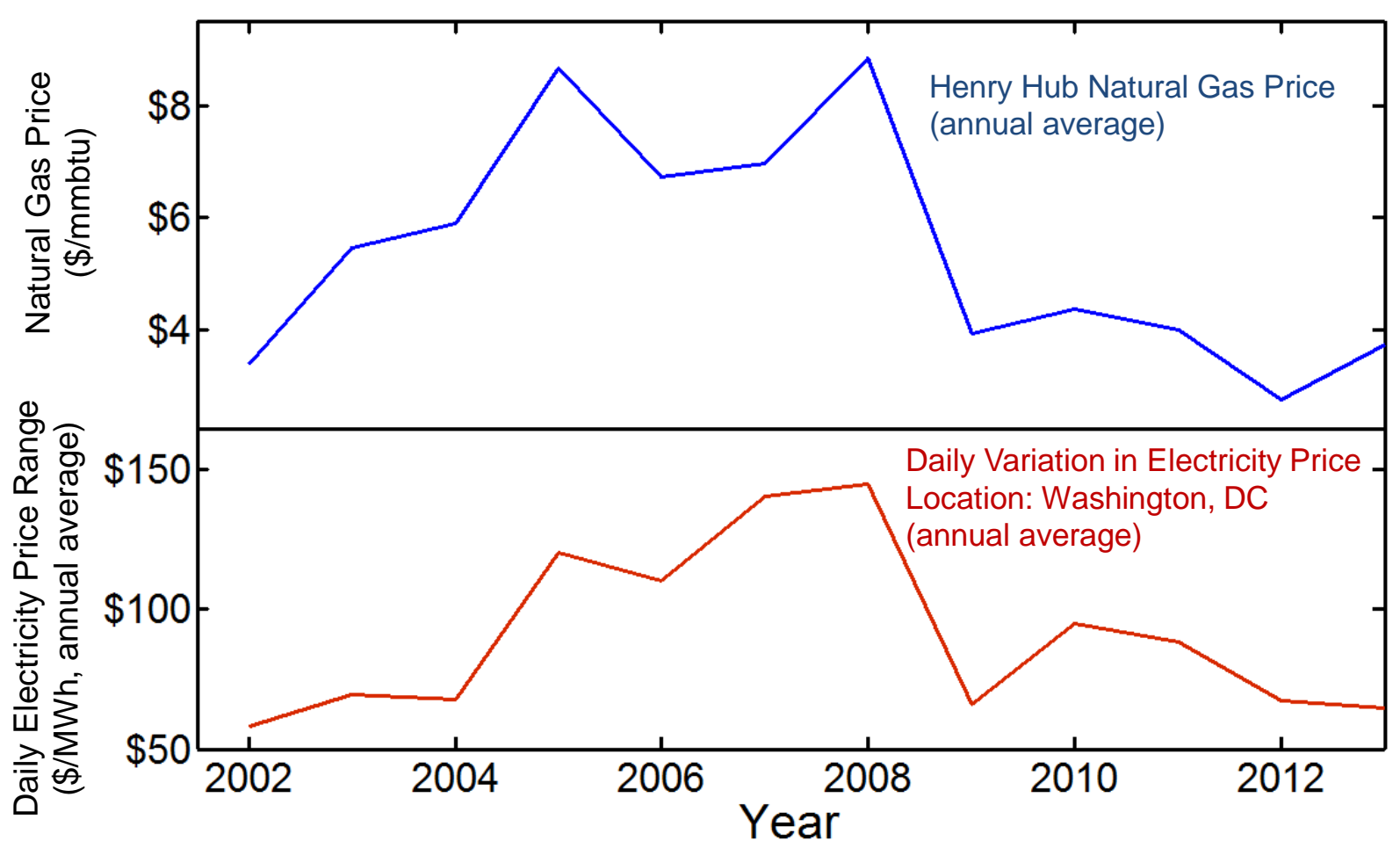

Figure 9: Henry hub natural gas prices and daily variability in electricity prices (Washington DC, annual average) from 2002 through 2013. When natural gas prices are high, daily price variability increases because of more expensive electricity from peaker natural gas turbines, which set the market price during peak hours. When natural gas prices decrease, peak price falls closer to the low off-peak prices set by coal/hydro/combined cycle plants. 


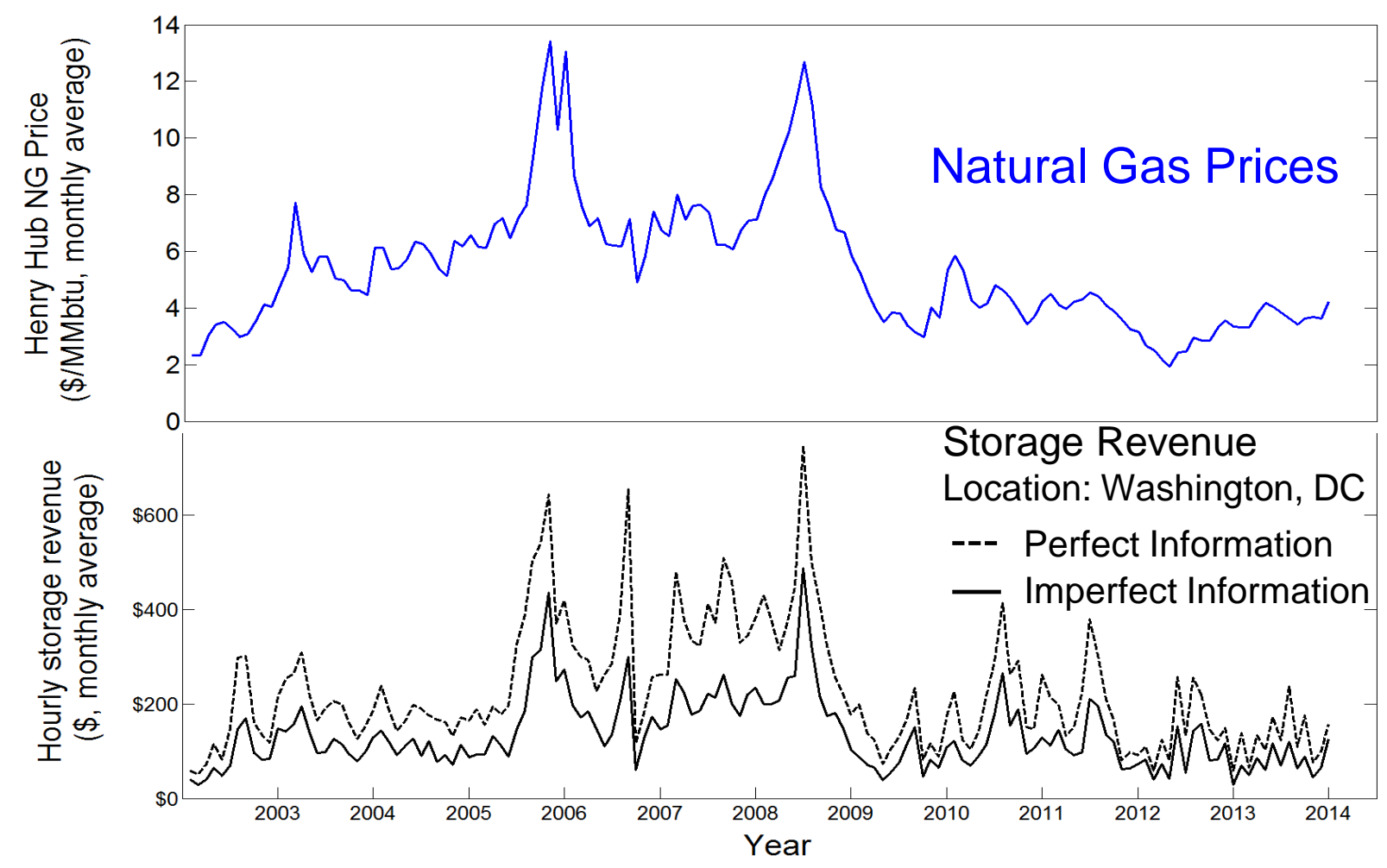

Figure 10: Monthly natural gas price and hourly energy arbitrage revenue from a storage device outside of Washington, DC under perfect and imperfect information. Energy arbitrage revenue is greater during periods of high natural gas price.
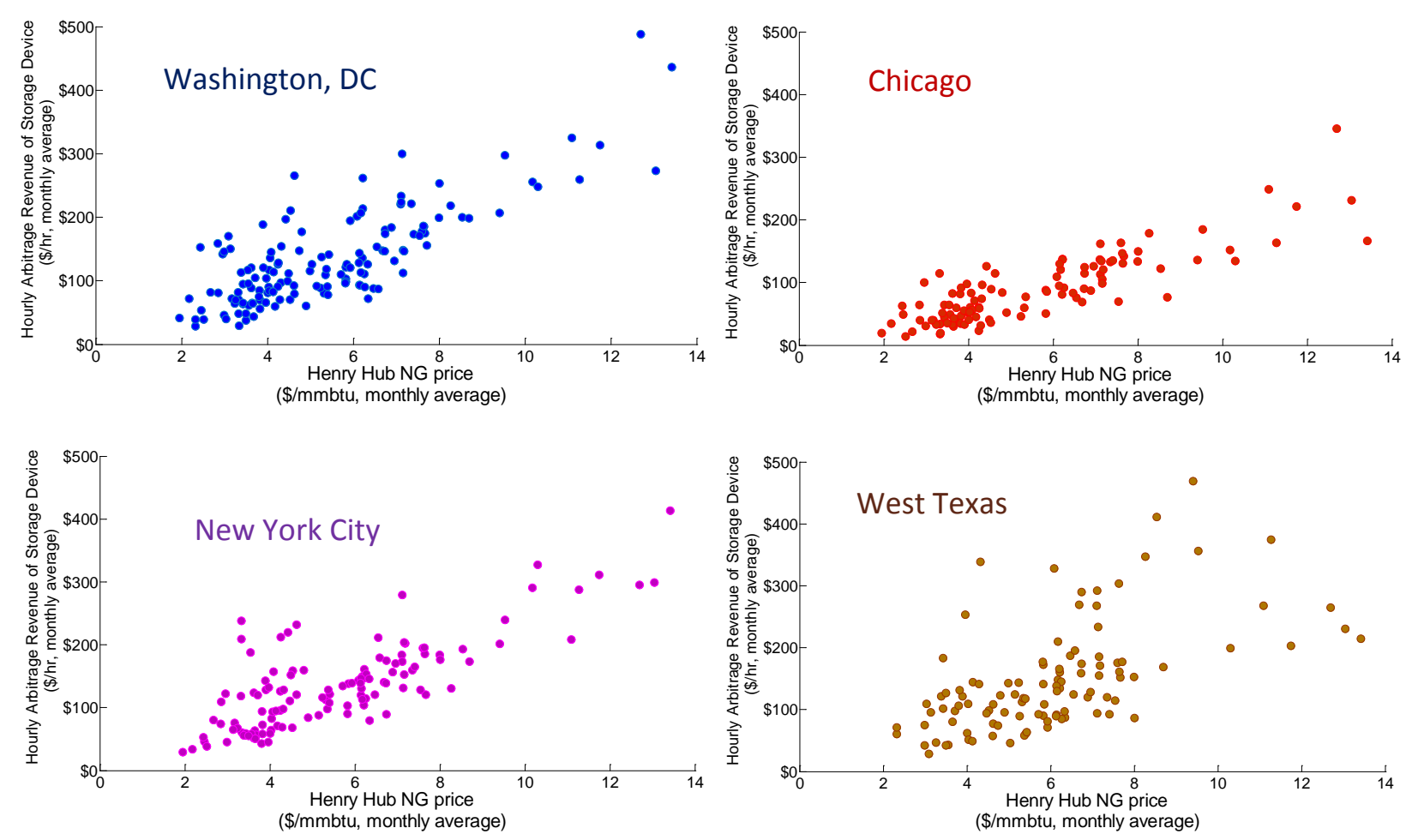

Figure 11: Plots of monthly average energy arbitrage revenue versus natural gas price for four locations: Washington, DC (upper left), Chicago (upper right), New York City (lower left), and West Texas (lower right). These results are for the 
imperfect information case applied to the $20 \mathrm{MW} / 80 \mathrm{MWh}$ (4-hour) system. The relationship is similar across locations, though the relative scale of the effect varies slightly.
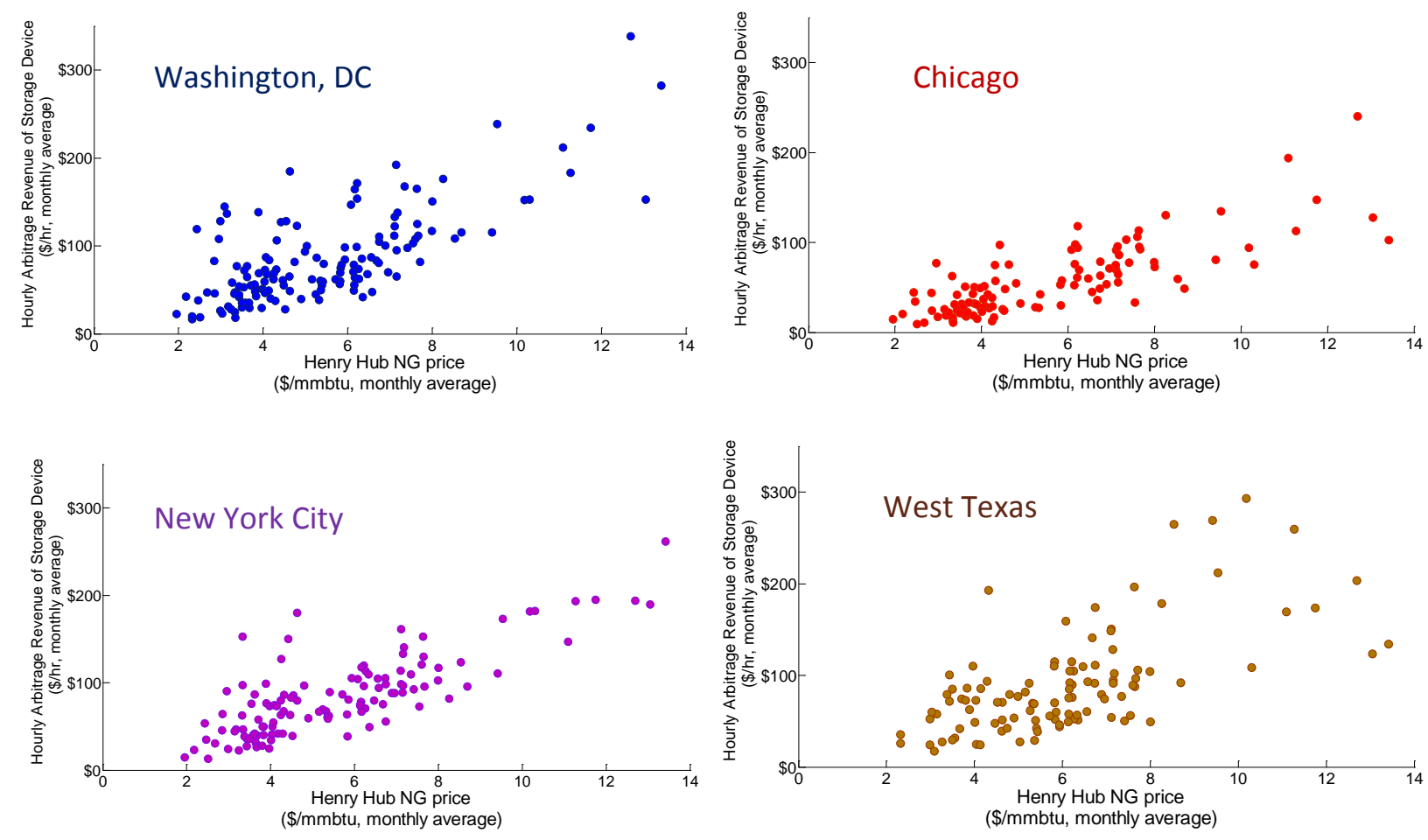

Figure 12: Plots of monthly average energy arbitrage revenue versus natural gas price for four locations: Washington, DC (upper left), Chicago (upper right), New York City (lower left), and West Texas (lower right). These results are for the imperfect information case applied to the $8 \mathrm{MW} / 80 \mathrm{MWh}$ (10-hour) system. The relationship is similar across locations, though the relative scale of the effect varies slightly. Due to the lower charge/discharge rate (10-hours), the average revenue is consistently lower than the revenue for the 4-hour system with the same energy capacity (note the change in yaxis scale between Figure 11 and Figure 12). 


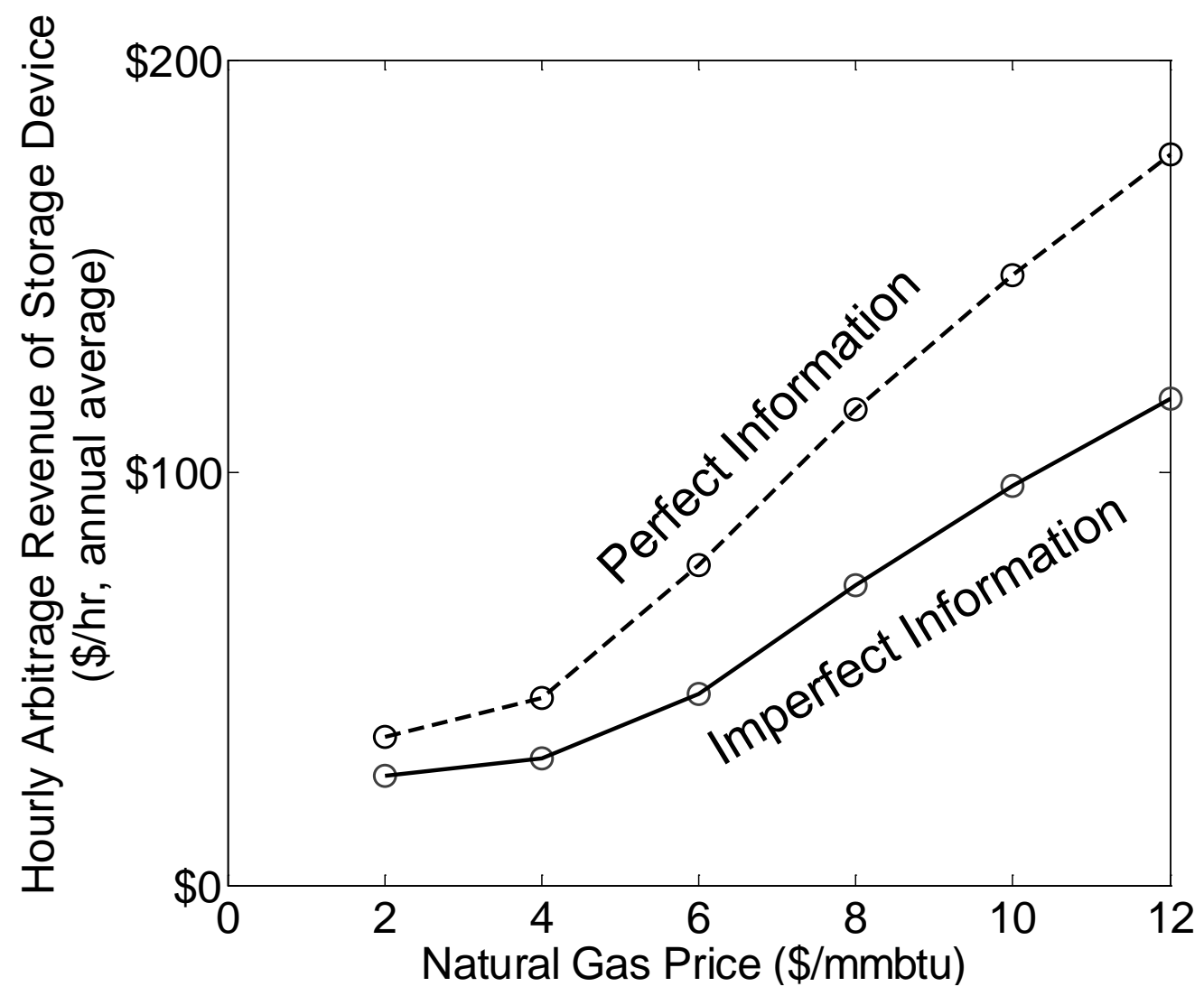

Figure 13: Annual average energy arbitrage revenue versus natural gas price, using PHORUM model to calculate hourly electricity prices. PHORUM results model the same year in all cases, with only the natural gas prices changed. As with actual price data, higher natural gas prices result in greater daily variability in electricity prices and therefore greater energy arbitrage revenue. PHORUM models the PJM system and is thus most comparable to the Washington, DC results in Figure 11. 

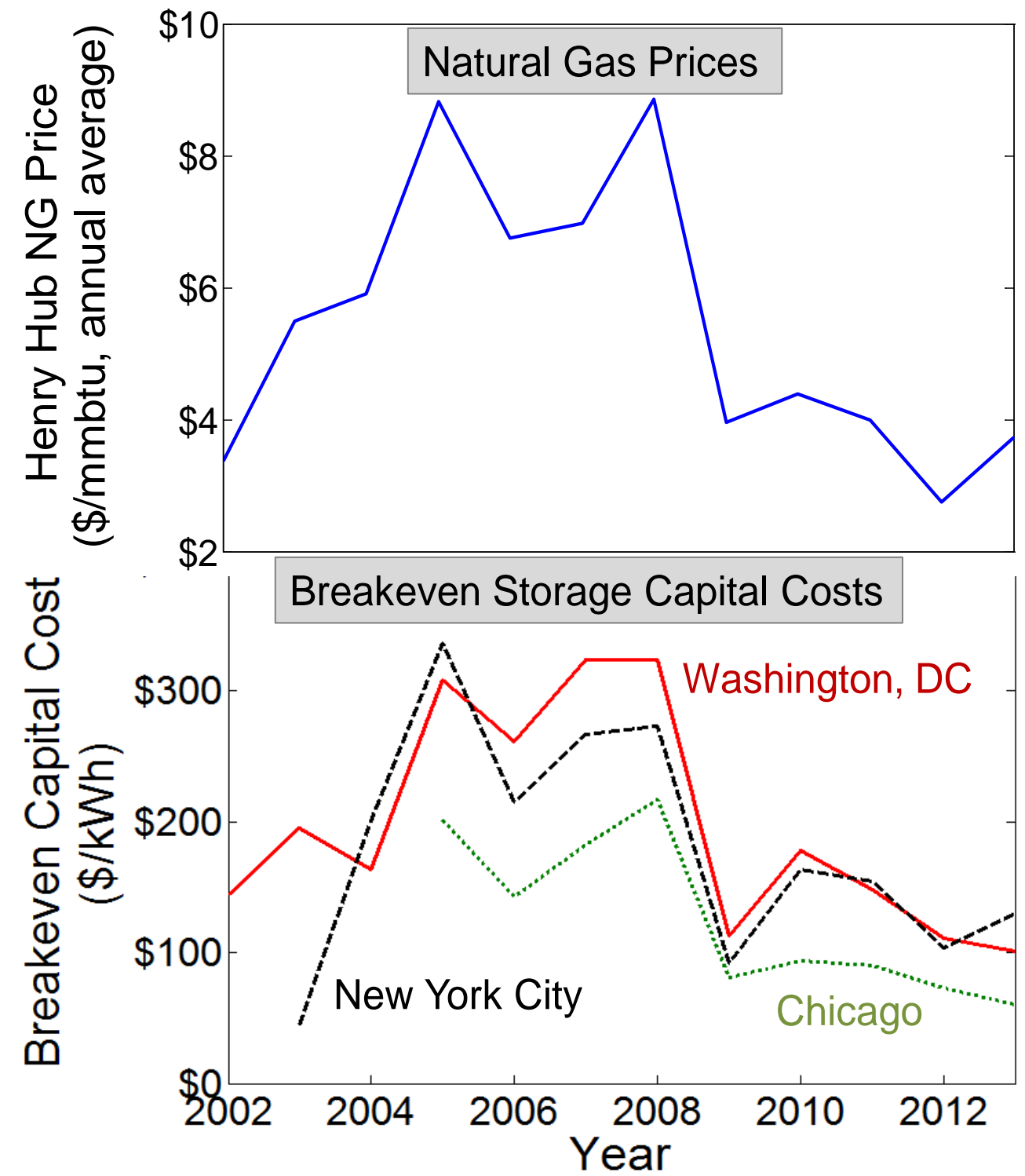

Figure 14: Natural gas prices and breakeven capital cost versus year for a storage device providing energy arbitrage service at three locations. These results imagine that the electricity price trends observed in a given year persist into the future - an assumption implicitly made when limited historical data are used to estimate future revenue. These results assume perfect information about future electricity prices and exclude all operating costs except for purchased electricity. Data availability for New York City and Chicago limit the range of years analyzed for those locations. In the 2005-2008 period, prevailing electricity prices would allow for storage with a cost in the $\mathbf{\$ 2 0 0}-\mathbf{\$ 3 0 0 / k W h}$ range to be profitable. Since 2009 , electricity prices have had lower daily variability, and storage capital cost must be less than $\$ 100 / k W h$ to be reliably profitable. The comparison with natural gas prices illustrates that the estimated breakeven capital cost of an arbitrage storage device is closely coupled with the natural gas price during the years covered by the applied electricity price data. 
Tables

Table 1. Operational U.S. storage projects larger than $20 \mathrm{MW}$, commissioned since 2000. Data are from the US Department of Energy Global Energy Storage Database (US Department of Energy, 2014). Thermal storage is excluded due to reporting oddities.

\begin{tabular}{|c|c|c|c|c|c|c|}
\hline Developer & Technology & $\begin{array}{l}\text { Rated } \\
\text { power } \\
{[\mathrm{MW}]}\end{array}$ & $\begin{array}{l}\text { Duration at } \\
\text { rated power } \\
\text { [minutes] }\end{array}$ & Primary use & $\begin{array}{l}\text { Commission } \\
\text { Date }\end{array}$ & State \\
\hline $\begin{array}{l}\text { Golden Valley } \\
\text { Electric Asssociation }\end{array}$ & $\mathrm{NiCd}$ & 27 & 15 & Spinning reserve & Dec 2003 & $A K$ \\
\hline Beacon Power, LLC & Flywheel & 20 & 15 & $\begin{array}{l}\text { Frequency } \\
\text { regulation }\end{array}$ & Jan 2011 & NY \\
\hline AES & Li-ion & 32 & 15 & $\begin{array}{l}\text { Frequency } \\
\text { regulation }\end{array}$ & Sept 2011 & WV \\
\hline Duke Energy & Lead acid & 36 & 40 & $\begin{array}{l}\text { Renewables } \\
\text { capacity firming }\end{array}$ & Oct 2012 & $T X$ \\
\hline $\begin{array}{l}\text { San Diego County } \\
\text { Water Authority }\end{array}$ & $\begin{array}{l}\text { Pumped } \\
\text { Hydro }\end{array}$ & 40 & 360 & Load Shifting & Sept 2012 & $\mathrm{CA}$ \\
\hline AES & Li-ion & 20 & not reported & $\begin{array}{l}\text { Frequency } \\
\text { regulation }\end{array}$ & Sept 2013 & $\mathrm{OH}$ \\
\hline Beacon Power, LLC & Flywheel & 20 & 15 & $\begin{array}{l}\text { Frequency } \\
\text { regulation }\end{array}$ & Jul 2014 & PA \\
\hline
\end{tabular}

Table 2: Base-case flywheel energy storage properties.

\begin{tabular}{|ll|}
\hline Flywheel Energy Storage Parameters & Base-Case Value \\
\hline Round-trip Efficiency & $90 \%$ \\
\hline Module Energy Capacity & $0.025 \mathrm{MWh}$ \\
\hline Module Power Limit & $0.1 \mathrm{MW}$ \\
\hline Flywheel Friction Losses & $3 \%$ of max power $(3 \mathrm{~kW})$ \\
\hline Fixed Operating Cost & \$5 / module - year \\
\hline Length of Capital Investment & 20 years \\
\hline
\end{tabular}


Table 3: Frequency regulation parameters.

\begin{tabular}{|ll|}
\hline Frequency Regulation Parameter & Value \\
\hline Modeled Period & 5 days \\
\hline Modeled Time Increment & 2 seconds \\
\hline Energy Purchase Time Increment & 900 seconds (15 minutes) \\
\hline Balancing Energy Cost & $\$ 40 / \mathrm{MWh}$ \\
\hline Cost of Capital Rate & $8 \%$ \\
\hline
\end{tabular}

Table 4: Energy arbitrage parameters.

\begin{tabular}{|ll|}
\hline Energy Arbitrage Parameter & Value \\
\hline Modeled Period & 1 year \\
\hline Modeled Time Increment & 1 hour \\
\hline Storage Plant Maximum Power & $20 \mathrm{MW}$ \\
\hline Storage Plant Energy Capacity & $80 \mathrm{MWh}$ \\
\hline Storage Plant Round-trip Efficiency & $75 \%$ \\
\hline Cost of Capital Rate & $8 \%$ \\
\hline
\end{tabular}

Table 5: PJM regression results, withholding missing fuel cost data. $R 2=0.51$

\begin{tabular}{|c|c|c|c|}
\hline Coefficient & Estimate & Standard error & Significance \\
\hline Constant & 17.4 & 17.7 & \\
\hline gasPrice $\left(\beta_{1}\right)$ & 2.5 & 0.5 & $* * *$ \\
\hline coalPrice $\left(\beta_{2}\right)$ & -0.4 & 0.3 & \\
\hline oilPrice $\left(\boldsymbol{\beta}_{3}\right)$ & 0.1 & 0.0 & $*$ \\
\hline
\end{tabular}

Table 6: NYISO regression results, withholding missing fuel cost data. $R 2=0.85$

\begin{tabular}{|c|c|c|c|}
\hline Coefficient & Estimate & Standard error & Significance \\
\hline Constant & 99 & 17.4 & $* * *$ \\
\hline gasPrice $\left(\boldsymbol{\beta}_{1}\right)$ & 4.0 & 0.5 & $* * *$ \\
\hline coalPrice $\left(\boldsymbol{\beta}_{2}\right)$ & -1.4 & 0.3 & $* * *$ \\
\hline oilPrice $\left(\beta_{3}\right)$ & -0.2 & 0.0 & $* * *$ \\
\hline
\end{tabular}

